\title{
Sources of sentence constraint on lexical ambiguity resolution
}

\author{
HOANG VU and GEORGE KELLAS \\ University of Kansas, Lawrence, Kansas \\ and \\ STEPHEN T. PAUL \\ Mississippi State University, Mississippi State, Mississippi
}

\begin{abstract}
Results from a series of naming experiments demonstrated that major lexical categories of simple sentences can provide sources of constraint on the interpretation of ambiguous words (homonyms). Manipulation of verb (Experiment 1) or subject noun (Experiment 2) specificity produced contexts that were empirically rated as being strongly biased or ambiguous. Priming was demonstrated for target words related to both senses of a homonym following ambiguous sentences, but only contextually appropriate target words were primed following strongly biased dominant or subordinate sentences. Experiment 3 showed an increase in the magnitude of priming when multiple constraints on activation converged. Experiments 4 and 5 eliminated combinatorial intralexical priming as an alternative explanation. Instead, it was demonstrated that each constraint was influential only insofar as it contributed to the overall semantic representation of the sentence. When the multiple sources of constraint were retained but the sentence-level representation was changed (Experiment 4) or eliminated (Experiment 5), the results of Experiments 1, 2, and 3 and were not replicated. Experiment 6 examined the issue of homonym exposure duration by using an 80-msec stimulus onset asynchrony. The results replicated the previous experiments. The overall evidence indicates that a sentence context can be made strongly and immediately constraining by the inclusion of specific fillers for salient lexical categories. The results are discussed within a constraint-based, context-sensitive model of lexical ambiguity resolution.
\end{abstract}

Research on lexical ambiguity resolution has dealt primarily with activation of the meanings of ambiguous words (e.g., homonyms) as a function of prior information. The majority of the literature on context effects has supported either the principles of modularity, in which an autonomous lexical processor (Fodor, 1983; Forster, 1979 ) is uninfluenced by syntax and semantics (see, e.g., Onifer \& Swinney, 1981; Seidenberg, Tanenhaus, Leiman, \& Bienkowski, 1982; Tanenhaus, Leiman, \& Seidenberg, 1979 ), or an interactive-activation framework in which syntax and semantics can immediately affect lexical processing (see, e.g., Marslen-Wilson \& Tyler, 1987; McClelland, 1987; Paul, Kellas, Martin, \& Clark, 1992; Simpson \& Krueger, 1991; Tabossi, Colombo, \& Job, 1987; Van Petten \& Kutas, 1987). Early research on lex-

Preparation of this article was supported by Biomedical Research Grant R15045 R05 awarded to G.K. and postdoctoral fellowship support from NIA Grant AG00030 to S.T.P. Experiments 1-4 constituted part of the first author's master's thesis, supervised by G.K. We acknowledge the assistance of Ruth Herman, Charles Martin, Robert Thornton, Leigh Smith, Steve Bray, and Julie Drey in stimulus construction and data collection. We thank Greg Simpson for helpful comments on an earlier draft of the manuscript. Requests for reprints should be addressed to G. Kellas, Department of Psychology, University of Kansas, Lawrence, KS 66045 (e-mail: gkellas@lark.cc.ukans.edu).

-Accepted by previous associate editor Kathryn T. Spoehr ical ambiguity resolution favored a modular position, but recently much evidence has accumulated in favor of an interactive position. It is not obvious as to what variables are contributing to the empirical differences, and, although a number of methodological issues have been raised (e.g., lexical decision task, stimulus onset asynchrony, intralexical priming), these explanations appear to be inadequate (see Simpson, 1994, for a review). Consequently, several researchers have proposed hybrid models that incorporate certain aspects of both views of lexical processing (see, e.g., Dopkins, Morris, \& Rayner, 1992; Duffy, Morris, \& Rayner, 1988; Garnham, 1985; Rayner, Pacht, \& Duffy, 1994; Simpson, 1984; Simpson \& Krueger, 1991; Tabossi \& Zardon, 1993)

The trend toward hybrid models has been motivated by recent research indicating that both meaning frequency and context play significant roles in ambiguity resolution. First, the alternative meanings of a homonym do not often occur equally in discourse. Instead, most homonyms are polarized, in which there is usually one frequently used (dominant) meaning, and one or more less frequently used (subordinate) meanings. The frequency with which a homonym's meanings are used has been shown to affect lexical processing (see, e.g., Dopkins et al., 1992; Duffy et al., 1988; Hogaboam \& Perfetti, 1975; Rayner \& Duffy, 1986; Simpson \& Burgess, 1985; Tabossi \& Zardon, 1993). For example, Hogaboam and Perfetti and Simpson 
and Burgess demonstrated that the dominant meaning of polarized homonyms becomes available sooner than the subordinate meaning. More recently, Tabossi and Zardon and Rayner and colleagues found processing of a polarized homonym to be facilitated when the context biased the dominant sense but not when the context biased the subordinate sense.

Second, research shows that context can be immediately influential in ambiguity resolution. For example, Tabossi et al. (1987) demonstrated that semantic features generated for a homonym in context can be primed by contexts denoting those features (e.g., the target SAFE was primed following the sentence The violent hurricane did not damage the ships which were in the PORT). Furthermore, it has become increasingly evident that the strength of the biasing context is a critical (and relatively ignored) parameter in the resolution of lexical ambiguity. The degree to which the alternative meanings of a homonym are activated is sensitive to the constraints imposed by the biasing context. According to this contextsensitive model of lexical ambiguity resolution, the process of meaning activation is continuous, whereby the activation levels of alternative meanings of a homonym are computed and a continuum of graded activation is produced, depending on the overall strength of context (see, e.g., Paul et al., 1992; Simpson, 1981; Simpson \& Krueger, 1991). Theoretically, it has been proposed that a priming context activates a constellation of semantic features representing what the sentence is about (cf. Just $\&$ Carpenter, 1987). The features activated are modulated on a word-by-word basis such that the final pattern of features is a product of semantic, syntactic, and pragmatic constraints (cf. Kawamoto, 1993; Kellas, Paul, Martin, \& Simpson, 1991; Paul et al., 1992; Schwanenflugel \& LaCount, 1988; Schwanenflugel \& Shoben, 1985; Tabossi et al., 1987). At any given point during sentence processing, the emerging ensemble of features will constrain activation of a subsequent word's meaning, with a simultaneous dampening of features no longer relevant or appropriate for the ongoing discourse. The final representation may be very specific, in that only one interpretation is possible, or very general, in that it is compatible with a broad range of interpretations. We surmised that a contextual representation may range in its degree of constraint, from weakly constraining (ambiguous) to highly constraining, with respect to the meanings of a homonym.

A context is considered ambiguous (nonconstraining) when the features representing the context are general enough to overlap with features representing each of the alternative meanings of a homonym. In contrast, a sentence context is considered strongly biased (highly constraining) when the activated features only overlap with one meaning of an ambiguous word. Empirical evidence from studies in which subjects rated the strength of context has confirmed the above arguments. Simpson (1981) and Simpson and Krueger (1991) showed that, when contexts were rated as ambiguous, facilitation was demon- strated for both meanings of a homonym, but, under strong contexts, only the contextually appropriate meaning was facilitated. Apparently, ambiguous contexts are general enough to support both senses of a homonym, but the constraints imposed by strong contexts will only allow one sense.

The overall results from research on strength of context and lexical ambiguity resolution are provocative in that they provide a unified account of the discrepant outcomes reported in the literature. The differential patterns of activation that have emerged may depend on whether the biasing context was sufficiently strong to preclude activation of the inappropriate meaning of a homonym. However, what have been left undetermined in this research area are the characteristics of a sentence that will produce strong contexts. Strength of context is currently undefined, because no provisions have been made regarding the sources of constraint that may contribute to the construction of a biased or nonbiased context. With the exception of an ambiguous word, there has been no lexical, syntactic, or semantic consistency between strongly biased or ambiguous sentences in previous research. Consequently, it is not possible to determine the characteristics of sentences that serve to modulate contextual strength. The present research was conducted to address this issue.

Simpson's (1981) and Simpson and Krueger's (1991) examination of strength of context effects on lexical ambiguity resolution have been criticized for not testing for immediate activation of a homonym's meanings (see, e.g., Rayner et al., 1994; Tabossi et al., 1987). Consequently, the pattern of results reported by Simpson may have been contaminated by integration processes following word meaning activation. In light of these criticisms, we wanted to investigate again the parameter of context strength on lexical ambiguity resolution. Furthermore, we made an attempt to identify the characteristics of a sentence that may contribute to the strength of the context by manipulating the level of specificity of lexical constituents. Multiple constraint-based approaches to lexical processing propose that each constituent in an input stream can provide a source of constraint on processing (see, e.g., McClelland, 1987). This assumption has been tested mainly in the area of syntactic ambiguity research, specifically attachment ambiguities (e.g., main verb/reduced relative, MacDonald, 1993; good agent/poor patient, Trueswell \& Tanenhaus, 1994; prepositional phrase, Taraban \& McClelland, 1988). However, there has been no systematic examination of whether individual lexical sources of constraint can also affect lexical ambiguity resolution. In Experiments 1 and 2, we had subjects rate the experimental stimuli varying only in a single lexical constituent to assess the strength of the biasing context. Rather than constructing different sentences with differing lexical constituents, the structure of a simple sentence was maintained, and one of its constituents was systematically replaced to determine whether it was sufficient to render a context biasing toward one or the other mean- 
ing of a homonym. Following the logic of multiple constraint-based models, we hypothesized that each major lexical category will provide a source of constraint on lexical processing. It is our goal to demonstrate that strength of context can be systematically manipulated to bias the alternative meanings of a homonym with the judicious selection of a single word to fill a lexical category (e.g., verb or subject noun).

In Experiment 3, we conjoined the sources of constraint to determine whether the magnitude of priming for the contextually appropriate meaning of a homonym was greater when multiple constraints converged on processing of the homonym. In Experiments 4 and 5, we eliminated combinatorial intralexical priming (cf. Duffy, Henderson, \& Morris, 1989) as a potential explanation of our data and proposed that a sentence-level interpretation best accounts for our pattern of results. Both experiments were designed to demonstrate that lexical sources of constraint are fundamental only insofar as each contributed to the overall sentence-level representation. That is, each constraint influenced target word naming only through its evolving relationship with the context, and not because of word-based associations per se. When the semantic representation of the sentence was constructed to be incompatible with target words related to the alternative senses of the homonyms (Experiment 4) or when the representation was eliminated by scrambling the constituents of the sentence (Experiment 5), the pattern of activation found for Experiments 1, 2, and 3 was not replicated, even though the lexical constituents were maintained. In Experiment 6, we decreased the exposure duration of the homonym to further examine the immediate influence of context on lexical ambiguity resolution.

We made two predictions regarding the present research. First, the parameter of contextual strength can be determined by manipulating the specificity of the verb or subject noun in a simple sentence structure. This will result in a corresponding change in the degree of constraint of the sentence-level representation. The representations will be rendered strongly biased when the lexical categories are specific and ambiguous when they are nonspecific. The degree of contextual constraint should be indexed by off-line ratings of sentence bias. Operationally, we define a verb or subject noun as being specific to the extent that it constrains the potential domain of reference described by the sentence. Verb and subject noun specificity can be illustrated with the following examples:

1. He located the bat.

2. He splintered the bat.

3. He wounded the bat.

4. The man located the bat.

5. The slugger located the bat.

6. The biologist located the bat.

In the first set of examples, the agent of the action and the direct object are identical; only the verbs are different. In each case, the class of verb is the same, a transitive verb requiring a direct object, but the verbs of (2) and (3) are more specific than that in (1). Of those things that may be located, only a subset may be splintered or wounded. Consequently, the verbs in (2) and (3) place constraints on what can fulfill the thematic role of the direct object. Similarly, the subject nouns of (5) and (6) are more specific than that in (4), because each is a particular member of the general class the man (or woman). Although these examples contain the same predicate, the subject noun fillers vary in specificity and differ in agentive roles. Although the agents are animate entities that can plausibly perform identical actions across examples, only a man (4) can be expected to locate either type of bat. In (5) and (6), the type of bat being located will depend on the expected activities associated with a slugger and $b i$ ologist, respectively. Although plausible, it would be unexpected of a slugger to locate a flying mammal and of a biologist to look for a baseball bat. In these latter examples, it is the subject noun that places constraints on the thematic role of the direct object filler BAT.

The second prediction was that such systematic modifications of contextual bias would be sufficient to produce different patterns of meaning activation. When the contexts are strongly biased (dominant or subordinate biased), naming latencies for target words would show priming for contextually appropriate meanings relative to unrelated conditions, whereas ambiguous contexts would prime both senses of the homonym.

\section{EXPERIMENT 1}

The verb of a sentence was our initial candidate for examining sources of contextual constraint on lexical ambiguity resolution, because of its centrality in linguistic research and linguistic theory. Generally, it is accepted that the verb determines the relationship among the arguments expressed by a sentence and is viewed as the "center of the action" (Kintsch, 1974; Sanford \& Garrod, 1981). Furthermore, the verb has been shown to provide constraints on the resolution of syntactic ambiguity (see, e.g., MacDonald, 1993; MacDonald, Pearlmutter, \& Seidenberg, 1994). The verbs used for this experiment were all transitive, requiring a direct object and a subject as the two grammatical constituents fulfilling the thematic object and agent roles, respectively. With systematic examination of the sentence prime being the goal, it was essential that the lexical constituents in the priming context remain constant, except for the constituent of interest. This condition of invariance was necessary to evaluate which constituent will (or will not) provide a source of constraint. The priming sentences were simple, consisting of a subject, verb, and direct object, with the direct object of the verb being a sentence-final ambiguous word. In addition, since only the verb was being evaluated, the subject of the sentence was kept general, with minimal semantic content (e.g., pronouns). Therefore, only the verb of the sentence was free to vary. For each homonym, three sentences were constructed such that manipulation of only the specificity of the verb would render the sentence 
Table 1

Examples of Sentence and Target Stimuli in Experiments 1 and 2

\begin{tabular}{|c|c|c|c|}
\hline \multirow{2}{*}{$\begin{array}{l}\text { Sentence } \\
\text { Primes }\end{array}$} & & \multicolumn{2}{|c|}{ Targets } \\
\hline & & Related & Unrelated \\
\hline \multicolumn{4}{|c|}{ Experiment 1} \\
\hline Amb & He located the bat. & & \\
\hline Dom & He splintered the bat. & WOODEN & SAFE \\
\hline Sub & He wounded the bat. & FLY & STATION \\
\hline Amb & He approached the base. & & \\
\hline Dom & He stole the base. & SAFE & WOODEN \\
\hline Sub & He patrolled the base. & STATION & FLY \\
\hline \multicolumn{4}{|c|}{ Experiment 2} \\
\hline $\mathrm{Amb}$ & The man located the bat. & & \\
\hline Dom & The slugger located the bat. & WOODEN & SAFE \\
\hline Sub & The biologist located the bat. & FLY & STATION \\
\hline Amb & The man approached the base. & & \\
\hline Dom & The runner approached the base. & SAFE & WOODEN \\
\hline Sub & The soldier approached the base. & STATION & FLY \\
\hline
\end{tabular}

dominant biased, subordinate biased, or ambiguous. To repeat, strongly biased sentences should prime one sense of the sentence-final homonym, whereas ambiguous sentences should prime both senses.

\section{Method}

Subjects. Forty-eight undergraduate volunteers from introductory psychology courses participated in the naming task. An additional 80 subjects were used to rate the stimuli. All the subjects received class credit and were native English speakers with normal or corrected-to-normal vision.

Stimuli. One hundred and fifty ambiguous words were selected from the association norms of Nelson, McEvoy, Walling, and Wheeler (1980) and Twilley, Dixon, Taylor, and Clark (1994). In order for the homonyms to fill the role of sentence-final direct objects, it was necessary for the selected homonyms to be of the noun/noun variety. Overall, the selected homonym corpus was polarized, with the dominant meanings having a probability range of $.51-1.00$, with a mean of .76. ${ }^{1}$ For each homonym, two lexical associates were selected, one representing the dominant and the other a subordinate meaning. Three sentence frames were constructed for each homonym, resulting in dominant, subordinate, and ambiguous contexts, for a total of 450 experimental sentences. Each sentence frame (1) ended with a homonym and (2) did not render the sentence-final homonym predictable, as indicated by Cloze probabilities (discussed below).

The particular bias of the experimental sentences was initially agreed on by a panel of four judges. Subsequently, the sentences were divided into two sets of 225 and randomly presented to two groups of 40 subjects each. The subjects rated the degree to which each sentence was biased toward the associatively related targets on a 7 -point scale (where 1 represented a strong bias toward the dominant meaning, and 7 represented a strong bias toward the subordinate meaning).

Strict criteria were used in selecting the experimental stimuli from the subjects' ratings. For each sentence triad, dominant biasing sentences were rated between 1.00 and $2.25(M=1.39, S D=$ $0.28)$, ambiguous sentences between 3.00 and $5.00(M=3.84, S D=$ 0.48 ), and subordinate biasing sentences between 5.75 and 7.00 $(M=6.50, S D=0.33)$. In order to ensure clear boundaries between prime conditions, no overlap was allowed among the ranges. On the basis of the above criteria, 96 sentence triads ( 288 sentences) were selected for study.
To determine the extent to which the biased sentence frames were predictive, Cloze probabilities were examined. Twenty additional subjects were given the 192 experimental sentences (minus the homonyms) that had been previously rated as strongly dominant or subordinate biased. The subjects were instructed to read the sentence frames carefully and to meaningfully complete each one with the first word that came to mind. Results showed that generation of the homonym and/or subsequent target words was extremely infrequent. For dominant biased sentence frames, the Cloze probabilities were .05 for homonyms and .04 for target words. For the subordinate biased sentence frames, the Cloze probabilities were .02 and .05 , for homonyms and target words, respectively. The low probabilities were taken as an indication that the sentence frames were not predictive of either the sentence-final homonym or subsequent target words.

Across lists and subjects, each sentence prime (dominant, subordinate, ambiguous) was paired with two related targets (dominant, subordinate). Unrelated conditions were created by randomly re-pairing related primes and targets, with no prime or target being repeated within subjects. Table 1 contains an example of the stimuli used for each of the conditions. ${ }^{2}$ The full set of sentence stimuli for Experiment 1 can be found in Appendix A. Targets were equated across conditions on number of letters (dominant, $M=5.2, S D=$ 1.5 ; subordinate, $M=5.5, S D=1.9$ ), number of syllables (dominant, $M=1.6, S D=0.80$; subordinate, $M=1.7, S D=0.90$ ), bigram frequency (dominant, $M=5,491, S D=3,888$; subordinate, $M=4,788$, $S D=4,076$; from Massaro, Taylor, Venezky, Jastrzembski, \& Lucas, 1980), and frequency of occurrence in the English language (dominant, $M=181, S D=733$; subordinate, $M=70, S D=101$; from Kučera \& Francis, 1967). There was no reliable difference found for any variable (all $p s>.15$ )

In order for each prime and target to appear only once per subject, with each subject exposed to all conditions, 12 stimulus lists were constructed. Each list consisted of an equal number of the 12 possible prime-target pairings (see example in Table 1), resulting in a total of 96 experimental trials per list. In addition, 24 sentences with different homonyms were taken from the remaining 450 rated sentences for reading rate calibration (discussed below), as well as another 24 for use as practice trials. These latter 48 trials were representative of the experimental conditions and were identical for all the subjects.

Apparatus. Stimuli were presented on an IBM compatible 386 personal computer with a NEC Multisync-Plus color monitor. A Shure Brothers microphone (Model 515SB), attached to a Grason- 
Table 2

Mean Naming Latencies (in Milliseconds), Standard Errors ( $S E$ ), Percent Errors, and Magnitude of Priming for Experiments 1 and 2

\begin{tabular}{|c|c|c|c|c|c|c|}
\hline \multirow[b]{3}{*}{ Target } & \multicolumn{6}{|c|}{ Prime Type } \\
\hline & \multicolumn{2}{|c|}{ Ambiguous } & \multicolumn{2}{|c|}{ Dominant } & \multicolumn{2}{|c|}{ Subordinate } \\
\hline & Dom & $\mathrm{Sub}$ & Dom & $\mathrm{Sub}$ & Dom & Sub \\
\hline \multicolumn{7}{|c|}{ Experiment 1} \\
\hline \multicolumn{7}{|l|}{ Related } \\
\hline$M$ & 619 & 629 & 615 & 636 & 634 & 622 \\
\hline$S E$ & 9.4 & 9.5 & 9.2 & 9.4 & 9.7 & 8.9 \\
\hline$\%$ Error & 1.3 & 2.3 & 2.1 & 2.3 & 2.1 & 5.9 \\
\hline \multicolumn{7}{|l|}{ Unrelated } \\
\hline$M$ & 640 & 644 & 634 & 633 & 637 & 641 \\
\hline$S E$ & 8.7 & 9.5 & 9.5 & 9.2 & 9.4 & 10.0 \\
\hline$\%$ Error & 2.1 & 2.9 & 2.1 & 5.7 & 3.4 & 3.6 \\
\hline Magnitude of priming & $21^{*}$ & $15^{*}$ & $19^{*}$ & -3 & 3 & $19^{*}$ \\
\hline \multicolumn{7}{|c|}{ Experiment 2} \\
\hline \multicolumn{7}{|l|}{ Related } \\
\hline$M$ & 644 & 645 & 641 & 660 & 654 & 640 \\
\hline$S E$ & 9.2 & 9.7 & 8.9 & 10.5 & 10.2 & 9.5 \\
\hline$\%$ Error & 1.6 & 3.1 & 2.9 & 2.1 & 0.8 & 2.1 \\
\hline \multicolumn{7}{|l|}{ Unrelated } \\
\hline$M$ & 660 & 655 & 663 & 662 & 658 & 663 \\
\hline$S E$ & 10.5 & 11.1 & 11.7 & 9.5 & 11.0 & 11.5 \\
\hline$\%$ Error & 2.1 & 3.4 & 1.3 & 4.4 & 3.6 & 3.4 \\
\hline Magnitude of priming & $16^{*}$ & $10 \dagger$ & $22^{*}$ & 2 & 4 & $23^{*}$ \\
\hline
\end{tabular}

Stadler E7300A-1 voice-operated relay (VOR), was interfaced with the computer to signal verbal responses. Stimulus presentation was synchronized to the refresh rate of the monitor, and response times were measured to the nearest millisecond from the onset of the target to the triggering of the VOR by the subject's vocal response.

Procedure. All the subjects were tested individually in a dimly lit room and were seated approximately $60 \mathrm{~cm}$ from the computer monitor such that targets subtended an average visual angle of about $1.6^{\circ}$ horizontally and $0.5^{\circ}$ vertically.

Whereas most research on word meaning activation employs a predetermined rate of presentation, we maintain that controlling for individual differences in reading rate will ensure a more precise estimate of the interstimulus interval (ISI) between presentation of the prime and the subsequent target word. Consequently, sentence presentation rate was calibrated for each subject prior to the experimental trials. The subjects were instructed to silently read the presented sentences at their normal reading rate and to read for comprehension. The set of 24 calibration sentences was presented one word at a time at an initial rate of $198 \mathrm{msec}$ per word. Each sentence was presented beginning at the left side and vertical center of the computer screen. Sentence primes were displayed in lowercase letters (with the exception of the first letter of the first word, which was capitalized), whereas targets were presented in uppercase letters in order to be visually distinguishable from the sentences. For each calibration trial, a series of word-length lines, each separated by a single space, was presented for $1 \mathrm{sec}$. The lines served as a warning signal and as location and length cues for the words constituting the upcoming sentence. The display format utilized a modified unfolding procedure in which each word of the sentence was presented one at a time and remained visible until the sentence-final word was completely displayed (cf. Just, Carpenter, \& Woolley, 1982). After each calibration trial, the subjects answered a wh-question about the sentence that had just been pre- sented. The subjects were then asked whether the display rate was too fast, too slow, or about right. The experimenter adjusted the exposure rate accordingly (in increments or decrements of about $16.7 \mathrm{msec}$ ) on the basis of the subjects' self-reports. In this manner, the optimal rate of presentation was achieved while still maintaining comprehensibility. After the calibration trials, the display rate was fixed for the remainder of the experiment.

Next, the subjects were given instructions for the naming task. The procedures for the naming task were the same as those for the calibration trials, except that, immediately following the sentencefinal word $(0$-msec ISI), the sentence was removed and a target word was displayed six character spaces to the right of where the sentence had previously ended. The subjects were instructed to name the target aloud as quickly and as accurately as possible. To safeguard against the strategy of not reading the sentences for comprehension, the subjects were asked to answer wh-comprehension questions on a random $20 \%$ of the trials.

Naming responses were monitored for accuracy and legality. Response errors included incomplete responses, mispronunciations, extraneous noises loud enough to trigger the VOR, and artificial delays resulting from responses that initially failed to trigger the VOR. All the trials were separated by a 2,500 -msec intertrial interval and responses to the first 24 naming trials constituted practice and were not examined.

\section{Results}

Two subjects were replaced due to a high rate of comprehension errors $(>40 \%)$, and two subjects were replaced due to excessive naming errors $(>10 \%)$. The subjects' mean calibrated reading speed was $252 \mathrm{msec}$ per word $(S D=42 \mathrm{msec})$. Response errors constituted only $3 \%$ of the data, and comprehension accuracy was $89.4 \%$.

Mean correct naming latencies were submitted to a prime type (ambiguous, dominant bias, subordinate bias) $\times$ target dominance (dominant, subordinate) $\times$ target relatedness (related, unrelated) analysis of variance (ANOVA) for repeated measures, with both subjects $\left(F_{1}\right)$ and items $\left(F_{2}\right)$ as random factors. All effects reported are significant at $p<.05$, unless otherwise indicated. Mean latencies, standard errors, percent errors, and the magnitude of priming are shown in Table 2.

An inspection of Table 2 shows that the naming latencies of contextually appropriate target words following both dominant and subordinate primes was facilitated relative to unrelated conditions, whereas latencies for inappropriate targets were not. On the other hand, naming latencies for both dominant and subordinate target words following ambiguous primes were facilitated, as compared with unrelated conditions. This description is supported by the following statistical outcomes.

The results revealed an effect of target relatedness $\left[F_{1}(1,47)=28.45, M S_{\mathrm{e}}=763.83 ; F_{2}(1,95)=9.81, M S_{\mathrm{c}}=\right.$ $3,635.17]$, where related targets were named faster than unrelated targets. This outcome was qualified by the interaction of prime type $\times$ target dominance $\times$ target relatedness $\left[F_{1}(2,94)=7.79, M S_{\mathrm{e}}=594.52 ; F_{2}(2,190)=2.94\right.$, $\left.M S_{\mathrm{e}}=2,581.58, p=.06\right] .^{3}$ No other main effects or interactions were significant.

The interaction was examined further by evaluating target dominance $\times$ target relatedness for each prime type separately. For the dominant prime condition, the 
only significant effect was the interaction of target dominance $\times$ target relatedness $\left[F_{1}(1,47)=8.67, M S_{\mathrm{e}}=\right.$ $\left.698.21 ; F_{2}(1,95)=7.44, M S_{\mathrm{e}}=1,713.39\right]$. As Table 2 indicates, dominant targets were facilitated following dominant primes relative to unrelated targets $[t(47)=$ $4.22, p<.001]$. On the other hand, subordinate targets showed no facilitation relative to unrelated targets $[t(47)=$ $0.47, p>.50]$.

An examination of the subordinate prime condition showed an opposite pattern of activation. There was an effect of target relatedness $\left[F_{1}(1,47)=8.29, M S_{\mathrm{e}}=715.14\right.$; $\left.F_{2}(1,95)=2.93, M S_{\mathrm{e}}=3,097.63, p=.09\right]$, which was qualified by an interaction of target dominance $\times$ target relatedness $\left[F_{1}(1,47)=4.76, M S_{\mathrm{e}}=697.92\right.$; but $F_{2}(1,95)=$ $\left.1.45, M S_{\mathrm{e}}=2,569.94, p=.23\right]$. Here, subordinate targets were facilitated relative to unrelated targets $[t(47)=3.38$, $p<.002]$. Responses to dominant targets, however, were not facilitated relative to unrelated targets $[t(47)=0.10$, $p>.50]$.

Finally, for the ambiguous prime condition, the only reliable effect was that of target relatedness $\left[F_{1}(1,47)=\right.$ $\left.12.84, M S_{\mathrm{e}}=1,171.32 ; F_{2}(1,95)=10.43, M S_{\mathrm{e}}=2,823.09\right]$. This outcome indicated that responses to targets related to both meanings of the homonym were facilitated, relative to unrelated targets.

Owing to a large number of cells with zeros for entries, a formal analysis of the error rates was not conducted. However, an inspection of the error rates and latencies in Table 2 provides no evidence of a speed-accuracy tradeoff. This conclusion was supported by the Pearson's correlation coefficient comparing naming latencies with error rates $(r=+.08)$.

\section{Discussion}

Experiment 1 demonstrated that the verb of simple sentences can provide a source of context strength. Activation of the alternative meanings of a homonym depended on the bias of the sentence context as a whole. This outcome agreed with the subjects' ratings of the stimuli, in that sentences rated as strongly biased only primed the contextually appropriate target words, whereas sentences rated as ambiguous primed both senses of the homonym. Apparently, manipulating the specificity of the verb was sufficient to change the semantic representation of the sentences, constraining the representation such that only one meaning of the ambiguous word was incorporated.

It is our position that lexical activation is determined by the semantic representation of a sentence context as $a$ whole. Whether the verb was general or specific only influenced the pattern of results insofar as the verb's meaning was incorporated in the sentence-level representation. In our view, features representing a context are activated and dampened over time as modified by each successive lexical item encountered. It is the emerging pattern of activated features during reading that determines the sentence-level representation. This resultant representation will reflect the overall contextual bias, which will immediately influence targets sharing similar features. The thrust of the preceding argument is that the verb is suf- ficient but not necessary in determining strength of context. This implies that other lexical categories (e.g., subject noun) may constrain a context as well. Experiment 2 was implemented to provide support for this argument.

\section{EXPERIMENT 2}

As with the verb, the subject noun of a sentence plays a privileged role in language comprehension. The subject noun often represents the topic of a sentence, serving as an address to which subsequent information will be connected (Sanford \& Garrod, 1981). Thus, it is argued that the subject noun receives the focus of the reader's attention. The design of this experiment involved holding the verb phrase constant while manipulating only the subject noun. It should be noted that this experiment utilized the ambiguous verb phrases from Experiment 1 (e.g., "located the bat"), which primed both senses of a homonym in the presence of nonspecific subjects (e.g., he or she). If it is the case that the verb is determining the pattern of activation for the sentence-final homonym in Experiment 1, the results of this experiment should show facilitation for both senses of the ambiguous word, regardless of the nature of the subject noun. On the other hand, if the activated features of a verb and other lexical categories are integrated with the features of the ongoing discourse to contribute to the overall contextual representation, changes to an ambiguous context that are expected to increase its bias should provide changes in meaning activation, even when the generality of the verb phrase remains fixed. Again, we predicted that manipulation of the subject noun alone would lead to priming of contextually appropriate target words when the sentences are rated as being strongly biased (dominant or subordinate), whereas sentences rated as ambiguous would prime targets related to both senses of the homonym.

\section{Method}

Subjects. Forty-eight undergraduates from an introductory psychology course participated in the naming task. An additional 135 subjects were used to rate the stimuli. All the subjects received class credit for participation and were native English speakers with normal or corrected-to-normal vision.

Stimuli. The original 150 ambiguous sentences from Experiment 1 , plus an additional 27 newly constructed ambiguous sentences, were used, bringing the total to 177 ambiguous sentences for Experiment 2. The additional homonyms were selected from the association norms of Twilley et al. (1994). For each of the 177 ambiguous sentences, the sentence-initial pronouns were systematically replaced with general or specific subject nouns. Subject nouns for biasing sentences were particular members of the class of general nouns in the ambiguous sentences. As a result, 3 sentences represented each ambiguous word, yielding a total of 531 experimental sentences. For each homonym, there was now a dominant biasing, a subordinate biasing, and an ambiguous sentence. Initially, the meaning bias of the sentences as a whole was agreed on by a panel of four judges. Table 1 contains an example of the stimulus conditions used in Experiment 2 . The full set of sentence stimuli for Experiment 2 can be found in Appendix B.

The 531 sentences were randomly mixed and separated into three lists of 177 sentences each. To ensure that the subjects did not acquire the strategy that sentences beginning with "The man," or 
"The woman" were indeed ambiguous, 144 ( 48 per list) biased filler sentences from the experimental stimuli of Experiment 1 were added $(21 \%)$. With the addition of the filler sentences, there were a total of 225 sentences per list. The three lists were given to three groups of 45 subjects each to rate. The rating scale was the same as that in Experiment 1.

The same criteria as those in Experiment 1 were used to select the experimental stimuli. Using these criteria, a total of 96 homonyms (and associated sentences) was selected. Each homonym was represented by 3 sentences (ambiguous, dominant bias, and subordinate bias), for a total of 288 experimental sentences. The means and standard deviations for the ratings of each sentence type were as follow: ambiguous prime $(M=3.89, S D=0.52)$; dominant prime $(M=1.60, S D=0.29)$; subordinate prime $(M=6.37, S D=0.30)$. Again, the selected homonym corpus was polarized, with the dominant meaning having a probability range of $.51-1.00$ with a mean of .77. Construction of unrelated conditions between primes and targets was the same as that in Experiment 1.

As before, sentences were constructed to avoid rendering the homonyms and/or the target words predictable. Because the current stimulus set differed from that in Experiment 1, sentence frames were again examined for predictiveness. Twenty subjects were given the 192 biased sentences with the sentence-final homonym deleted and asked to perform the Cloze task. For the dominant prime condition, the Cloze probabilities were .07 for homonyms and .08 for target words. For the subordinate prime condition, the Cloze probabilities were .05 and .10 for homonyms and target words, respectively. The low Cloze probabilities were taken as an indication that the biasing sentences, in general, were not predictive.

Sentences that were not selected as experimental stimuli were used to construct reading rate calibration and practice trials (24 each). Targets were equated across conditions on number of letters (dominant, $M=5.1, S D=1.6$; subordinate, $M=5.5, S D=2.0$ ), syllables (dominant, $M=1.5, S D=0.80$; subordinate, $M=1.7$, $S D=0.90$ ), bigram frequency (dominant, $M=5,034, S D=3,588$; subordinate, $M=4,873, S D=4,702$; from Massaro et al., 1980), and frequency of occurrence in the English language (dominant, $M=$ $154, S D=689$; subordinate, $M=95, S D=233$; from Kučera $\&$ Francis, 1967; all $p \mathrm{~s}>.10$ ).

Apparatus and Procedure. These were the same as those in Experiment 1 .

\section{Results}

Three subjects were replaced due to a high rate of comprehension errors $(>40 \%)$ and one subject was replaced due to excessive naming errors $(>10 \%)$. The subjects' average calibrated reading speed was $305 \mathrm{msec}$ per word $(S D=31 \mathrm{msec})$. Naming errors constituted $2.6 \%$ of the data and were excluded from subsequent analyses. Comprehension accuracy was $88.2 \%$.

Mean correct naming latencies were submitted to a prime type $\times$ target dominance $\times$ target relatedness ANOVA for repeated measures, with both subjects $\left(F_{1}\right)$ and items $\left(F_{2}\right)$ as random variables. All effects reported are significant at $p<.05$, unless otherwise indicated. Mean latencies, standard errors, percent errors, and the magnitude of priming are shown in Table 2.

An examination of Table 2 indicates that the naming latencies for target words following both dominant and subordinate primes were facilitated when these targets were appropriate but not when inappropriate, as compared with unrelated targets. Under the ambiguous prime con- dition, however, both dominant and subordinate target words were facilitated, as compared with unrelated targets. This description is supported by the following statistical outcomes.

There was a reliable effect of target relatedness $\left[F_{1}(1,47)=12.24, M S_{\mathrm{e}}=1,959.07 ; F_{2}(1,95)=10.75\right.$, $M S_{\mathrm{e}}=4,470.23$ ], where related targets were named faster than unrelated targets. This effect was qualified by the interaction of prime type $\times$ target dominance $\times$ target relatedness $\left[F_{1}(2,94)=4.12, M S_{\mathrm{e}}=1,077.54 ; F_{2}(2,190)=\right.$ $\left.2.51, M S_{\mathrm{e}}=2,498.39, p=.08\right]$. No other main effects or interactions were significant.

The above interaction was examined further by evaluating target dominance $\times$ target relatedness for each prime type separately. For the dominant prime condition, there was an effect of target relatedness $\left[F_{1}(1,47)=5.81\right.$, $\left.M S_{\mathrm{e}}=1,215.61 ; F_{2}(1,95)=4.97, M S_{\mathrm{e}}=3,147.83\right]$, which was qualified by the interaction of target dominance $X$ target relatedness $\left[F_{1}(1,47)=4.20, M S_{\mathrm{e}}=1,092.15\right.$; $\left.F_{2}(1,95)=2.82, M S_{\mathrm{e}}=2,599.84, p=.10\right]$. As Table 2 indicates, responses to dominant targets were facilitated following dominant primes, relative to unrelated targets $[t(47)=2.65, p<.02]$. However, responses to subordinate targets showed no evidence of facilitation, relative to unrelated targets $[t(47)=0.41, p>.50]$.

The results for the subordinate prime condition showed an opposite pattern. There was a significant effect of target relatedness $\left[F_{1}(1,47)=5.66, M S_{\mathrm{e}}=1,609.64\right.$; $\left.F_{2}(1,95)=5.92, M S_{\mathrm{e}}=2,620.86\right]$, which was qualified by the interaction of target dominance $\times$ target relatedness $\left[F_{1}(1,47)=5.34, M S_{\mathrm{e}}=755.00\right.$; but $F_{2}(1,95)=1.17$, $\left.M S_{\mathrm{e}}=4,094.64, p=.28\right]$. Here, responses to subordinate targets were facilitated following subordinate primes, relative to unrelated targets $[t(47)=3.31, p<.002]$. Conversely, responses to dominant targets were not facilitated $[t(47)=0.68, p>.40]$.

Finally, an analysis of the ambiguous prime condition revealed only an effect of target relatedness $\left[F_{1}(1,47)=\right.$ $\left.5.81, M S_{\mathrm{e}}=1,356.28 ; F_{2}(1,95)=5.45, M S_{\mathrm{e}}=3,105.60\right]$. The effect of target relatedness indicated that responses to targets related to both meanings of the homonym were facilitated, relative to unrelated targets.

Again, a formal analysis of error rates was not conducted due to a large number of cells with zeros for entries. ${ }^{4}$ However, the pattern of data in Table 2 provides no evidence for a speed-accuracy tradeoff $(r=+.16)$.

\section{Discussion}

Experiment 2 demonstrated that another source of contextual strength is the subject noun of simple sentences, and the results converged with the outcomes of Experiment 1 . As before, the results confirmed the subjects' strength of bias ratings by demonstrating immediate priming of the contextually appropriate meaning of a homonym following strongly biased sentences but priming for both meanings for sentences rated as ambiguous. 
In the presence of nonspecific verb phrases that had previously supported both senses of the homonyms, only the contextually appropriate target words were primed with the addition of specific subject nouns. Apparently, these subject nouns provided additional constraining information that was previously lacking in the ambiguous verb phrases.

Thus far, we have established that the verb and subject noun can provide constraints on the semantic representation of sentences. By manipulating these lexical categories to be general or specific, the representations of sentences were altered to incorporate one, the other, or both meanings of a homonym. A point of inquiry is how a specific lexical constituent contributes to a biasing context. We assume that it is the core meaning of the particular verb or subject noun, as each contributes to the sentence-level representation, that is providing the necessary biasing information. By core meaning, we refer to the conceptual representations of nouns and verbs, independent of their respective syntactic or thematic role functions. We assume the representations are coded by semantic features. An examination of Table 1 shows that structurally (i.e., syntactically) the verbs used in Experiment 1 were similar: transitive verbs requiring thematic roles for two arguments. These arguments are realized by the same general agent of the action (e.g., he or she) and direct object filler (the homonym) across the stimuli, and yet the meanings conveyed by the sentences are entirely different. Since the sentence structures are identical and the pronoun subject provides minimal semantic content, such differences must be attributed to lexical semantics that are internal to the verbs. When the class of verbs is general, such as located, multiple representations of the context are possible because the verb does not constrain the homonym to any particular meaning but instead supports multiple meanings. However, when the verb class is more specific, such as splintered or wounded, the domain of reference is reduced, because these verbs require specific direct object fillers. Only the baseball sense of bat can be splintered, and only the animate sense of bat can be wounded.

In Experiment 2, the subject noun in conjunction with a general verb and a sentence-final homonym, formed a sentence-level representation that also incorporated one, the other, or both meanings of a homonym, depending on the specificity of the subject noun. Again, the structure of the sentences and the verb phrases are identical across conditions, and yet the meaning conveyed by the contexts are different. These differences must be attributed to the lexical semantics of each particular subject noun. Consider that a sentence such as "The slugger located the bat" is literally ambiguous. A slugger is simply a particularization of the broader category of man or woman and clearly could locate a flying mammal as well as a wooden stick. Therefore, the results could have demonstrated facilitation for both meanings of bat. Instead, the results indicate that only the sports meaning of bat was activated. Apparently, the subject noun, serving as the sentence topic, invokes a situational representation wherein the specific referent of the subject noun is established in relation to a frequently expected activity of a slugger (e.g., searching for his baseball bat). Only those features that are relevant for a slugger are incorporated into the overall representation. Thus, a specific subject noun can provide additional constraining features to a sentence representation that a general subject noun cannot.

Our experiments indicate that constraints on sentencelevel representations can arise from multiple sources. If each major lexical item in a sentence can contribute to the semantic representation of that sentence, simultaneous satisfaction of multiple constraints may possibly increase the magnitude of priming effects. This coincides with our earlier assumption that the degree of constraint imposed by a context representation lies on a continuum and is indirectly supported by Taraban and McClelland (1988), whose research demonstrated that lexical processing was expedited when multiple constraints converged on a target word. Optimal processing occurred when the multiple constraints of phrasal attachment, thematic role, and thematic role fillers were simultaneously satisfied. Failure to satisfy any one of these constraints resulted in a systematic increase in reading times. It was our prediction that the combination of a specific verb and subject noun would place stronger constraints on meaning activation than either alone, resulting in relatively greater priming effects for contextually related target words. Alternatively, if a contextual representation could not be constructed to be any more specific and activation is at asymptotic levels (i.e., conjoining of constraints does not raise activation levels any higher), there would be no further increase in priming, and the amount of facilitation between related and unrelated targets should not increase in magnitude. Experiment 3 was implemented to test these hypotheses.

\section{EXPERIMENT 3}

In the present experiment, the specific verbs and subject nouns that were independently evaluated earlier were juxtaposed in a sentence context. For example, the verb from the sentence "He splintered the bat" was combined with the subject noun from the sentence "The slugger located the bat." Note that the referent of the pronoun is unspecified in the first sentence, whereas the second sentence, although empirically constraining, is literally ambiguous. By combining slugger with splintered to form the sentence "The slugger splintered the bat," a referent for the pronoun is explicitly instantiated and the sentence as a whole is disambiguated. Consequently, the situation described by the sentence is fully specified. It was predicted that combining the two specific lexical categories into one sentence would increase the bias of the dominant and subordinate contexts, which would perhaps increase the magnitude of priming effects for the contextually appropriate target words, relative to Experiments 1 and 2 . 
Table 3

Examples of Sentence and Target Stimuli in Experiments $3^{*}$ and 4

\begin{tabular}{|c|c|c|c|}
\hline \multirow{2}{*}{$\begin{array}{c}\text { Sentence } \\
\text { Primes }\end{array}$} & & \multicolumn{2}{|c|}{ Targets } \\
\hline & & Related & Unrelated \\
\hline \multicolumn{4}{|c|}{ Experiment 3} \\
\hline Dom & The slugger splintered the bat. & WOODEN & SAFE \\
\hline Sub & The biologist wounded the bat. & FLY & STATION \\
\hline Dom & The runner stole the base. & SAFE & WOODEN \\
\hline Sub & The soldier patrolled the base. & STATION & FLY \\
\hline \multicolumn{4}{|c|}{ Experiment 4} \\
\hline Dom & The slugger splintered the bone. & WOODEN & SAFE \\
\hline Sub & The biologist wounded the dog. & FLY & STATION \\
\hline Dom & The runner stole the trophy. & SAFE & WOODEN \\
\hline Sub & The soldier patrolled the streets. & STATION & FLY \\
\hline
\end{tabular}

\section{Method}

Subjects. The subjects were 48 undergraduates from an introductory psychology course. All the subjects received class credit for participation and were native English speakers with normal or corrected-to-normal vision.

Stimuli. Only those homonyms that were used in both Experiments 1 and 2 were selected. Of these, 36 were chosen to meet the requirements of the experimental design. Two sentences were constructed for each homonym (dominant and subordinate biased) by placing the dominant subject noun with the dominant verb and the subordinate subject noun with the subordinate verb. List construction, selection of calibration, and practice trials followed the same procedures as before. Table 3 contains an example of the stimulus conditions. The full set of sentence stimuli can be found in Appendix $C$.

As before, 20 subjects were given the 72 biased sentences with the sentence-final homonyms deleted and asked to perform the Cloze task. For the dominant prime condition, the Cloze probabilities were $p=.14$ for homonyms and $p=.03$ for subsequent target words. For the subordinate prime condition, the Cloze probabilities were $p=.08$ and $p=.12$ for homonyms and target words, respectively. Again, the low Cloze probabilities indicated that, in general, the sentence frames were not predictive.

Apparatus and Procedure. These were identical to those in the previous experiments.

\section{Results}

Two subjects were replaced due to a high rate of comprehension errors $(>40 \%)$, and two subjects were replaced due to excessive naming errors $(>10 \%)$. The subjects' average calibrated reading speed was $237 \mathrm{msec}$ per word $(S D=33 \mathrm{msec})$. Naming errors constituted only $4.9 \%$ of the total data and were excluded from subsequent analyses. Comprehension accuracy was $80 \%$.

Mean correct naming latencies were submitted to a prime type $\times$ target dominance $\times$ target relatedness ANOVA for repeated measures, using both subjects $\left(F_{1}\right)$ and items $\left(F_{2}\right)$ as random variables. All effects reported are significant at $p<.05$, unless otherwise indicated. Mean latencies, standard errors, percent errors, and the magnitude of priming are shown in Table 4.

An examination of Table 4 indicates that the naming latencies for target words following both dominant and subordinate primes were facilitated when these targets were appropriate but not when inappropriate, as compared with unrelated conditions. This description is supported by the following statistical outcomes.

There was a reliable effect of target relatedness $\left[F_{1}(1,47)=7.45, M S_{e}=4,103.83 ; F_{2}(1,35)=2.42, M S_{\mathrm{e}}=\right.$ $10,691.93, p=.13]$ and a significant interaction of prime type $\times$ target type $\left[F_{1}(1,47)=7.60, M S_{\mathrm{e}}=4,571.16\right.$; $\left.F_{2}(1,35)=5.58, M S_{\mathrm{e}}=4,874.22\right]$. The main effect and interaction were qualified by the interaction of prime type $X$ target dominance $\times$ target relatedness $\left[F_{1}(1,47)=10.86\right.$, $\left.M S_{\mathrm{e}}=4,516.64 ; F_{2}(1,35)=3.57, M S_{\mathrm{e}}=7,424.11, p=.07\right]$. No other main effects or interactions were significant.

The three-factor interaction was examined further by evaluating target dominance $\times$ target relatedness for each prime type separately. For the dominant prime condition, there was only an interaction of target dominance $X$ target relatedness for subjects but not items analyses $\left[F_{1}(1,47)=\right.$ $4.20, M S_{\mathrm{e}}=5,362.75 ; F_{2}(1,35)=0.78, M S_{\mathrm{e}}=10,678.52$, $p=.38]$. As Table 4 indicates, however, responses to dominant targets were facilitated following dominant primes, relative to the unrelated condition $[t(47)=3.43, p<.002]$. Responses to subordinate targets showed no evidence of facilitation relative to the unrelated condition $[t(47)=$ $0.46, p>.50]$.

Results for the subordinate prime condition showed an opposite pattern. There was a reliable effect of target relatedness $\left[F_{1}(1,47)=7.83, M S_{\mathrm{e}}=3,118.46 ; F_{2}(1,35)=\right.$ $\left.2.68, M S_{\mathrm{e}}=8,166.67, p=.11\right]$ and target dominance $\left[F_{1}(1,47)=7.13, M S_{\mathrm{e}}=3,152.68 ; F_{2}(1,35)=1.62, M S_{\mathrm{e}}=\right.$ $5,402.69, p=.21]$. These effects were qualified by the interaction of target dominance $\times$ target relatedness $\left[F_{1}(1,47)=8.40, M S_{\mathrm{e}}=3,164.93 ; F_{2}(1,35)=2.82, M S_{\mathrm{e}}=\right.$ $6,859.67, p=.10]$. As shown in Table 4, responses to subordinate targets were facilitated following subordinate primes, relative to the unrelated condition $[t(47)=3.92$, $p<.001]$. Conversely, responses to dominant targets were not facilitated $[t(47)=0.09, p>.50]$.

In order to assess our prediction that the convergence of multiple constraints on meaning activation would increase the magnitude of priming for appropriate target words over single constraints, we independently compared 
Table 4

Mean Naming Latencies (in Milliseconds), Standard Errors (SE), Percent Errors, and Magnitude of Priming for Experiments 3 and 6

\begin{tabular}{lccccc}
\hline & \multicolumn{3}{c}{ Experiment 3: Prime Type } \\
\cline { 2 - 3 } \multicolumn{1}{r}{ Target } & \multicolumn{2}{c}{ Dominant } & & \multicolumn{2}{c}{ Subordinate } \\
\cline { 2 - 3 } \cline { 5 - 6 } & Dom & Sub & & Dom & Sub \\
\hline Related & 715 & 753 & 754 & 709 \\
$M$ & 16.7 & 21.0 & 17.7 & 15.2 \\
$S E$ & 5.6 & 3.5 & 4.2 & 2.1 \\
\% Error & & & & \\
Unrelated & 749 & 744 & 753 & 755 \\
$M$ & 20.0 & 20.7 & 17.5 & 18.2 \\
$S E$ & 5.6 & 8.3 & 4.9 & 6.9 \\
$\%$ Error & $34 *$ & -9 & -1 & $46^{*}$ \\
Magnitude of priming & & & &
\end{tabular}

Experiment 6: Prime Type

\begin{tabular}{lcccccc} 
& Dom & Sub & Dom & Sub & Dom & Sub \\
\cline { 2 - 7 } Related & & & & & & \\
$M$ & 815 & 821 & 813 & 833 & 842 & 818 \\
$S E$ & 14.5 & 16.2 & 17.5 & 17.2 & 18.7 & 18.0 \\
\% Error & 2.0 & 7.6 & 2.0 & 5.6 & 4.2 & 2.0 \\
Unrelated & & & & & & \\
$M$ & 831 & 837 & 844 & 832 & 843 & 846 \\
$S E$ & 19.2 & 19.8 & 17.8 & 16.0 & 19.8 & 17.5 \\
\% Error & 4.2 & 2.8 & 2.8 & 5.6 & 2.8 & 4.9 \\
Magnitude of priming & $16^{*}$ & $16^{*}$ & $31^{*}$ & -1 & 1 & $28 *$ \\
\hline Note-Dom, dominant; Sub, subordinate. & *Significant, $p<.05$.
\end{tabular}

the noun + verb constraints of Experiment 3 with the verb constraint of Experiment 1, as well as with the subject noun constraint of Experiment 2. However, overall latencies were longer in Experiment 3, which we attribute to subject sampling error. Nonetheless, this may have contributed to the relative increase in magnitude of priming. To take into account latency differences among experiments, prime magnitude was calculated by the formula, (unrelated - appropriate related)/unrelated for each experiment. The results showed that the appropriate targets in Experiment 3 did receive significantly more priming than those in Experiment 1 [ 40 vs. $19 \mathrm{msec} ; t(94)=1.83$, $p=.035$, one-tailed]. Comparison of Experiment 3 with Experiment 2 provided similar results [ 40 vs. $22 \mathrm{msec}$; $t(94)=1.69, p=.047$, one-tailed] .

\section{Discussion}

The results of Experiment 3 converged with those outcomes obtained for Experiments 1 and 2, by showing that only the contextually appropriate meanings of homonyms were primed when the contexts were strongly biased. In addition, when the subject noun + verb constraints were conjoined, there was an increase in the magnitude of priming, as compared with only one source of constraint being present. Our results are readily interpreted by constraintbased models of lexical processing that propose that word meanings are computed and there is a continuum of graded activation. The combination of multiple constraints boosted the activation level of the contextually appropri- ate meaning higher than did a single constraint, perhaps through a more enriched sentence-level representation sharing more overlapping features with the appropriate target word.

The previous experiments provide evidence that meaning activation is context sensitive and that strength of context is a critical parameter in lexical ambiguity resolution. Furthermore, we have systematically demonstrated that individual constituents making up a sentence can provide the sources of constraint. However, our position is that each constituent is only influential because of its evolving relationship with the overall sentence-level representation. That is, each constituent can only provide a source of constraint so long as both the syntactic structure and the semantic representation of the sentence remain coherent. An immediate concern was that the obtained results were due to word-based priming from the verb in Experiment 1 and the subject noun in Experiment 2 to the target words. According to an intralexical priming account, priming of target words is not due to the semantic representation of the sentence per se but is instead a direct result of an associative relationship between an individual word in a sentence and the target word. Furthermore, because both the specific verb and the subject noun were juxtaposed in the sentences of Experiment 3, there was a greater potential for intralexical priming of the target words to have occurred. This recalls the research of Duffy et al. (1989), where simple intralexical priming was discarded in favor of a combinatorial model in which two content words in a sentence can combine to prime a subsequent target word. Note that this updated version of word-based priming still excludes the influence of the larger context. Although we subscribe to word-based priming of lexical associates in isolation and of contiguous words in context, we do argue, however, that priming effects observed in connected discourse extend beyond intralexical priming and cannot be dismissed purely on the basis of such claims (see, also, Foss, 1982; Hess, Foss, \& Carroll, 1996). We predict that, even when multiple sources of potential lexical associates to a target word are present, no priming will occur if the semantic representation of a sentence as a whole is changed to be incompatible with the target word. By changing the direct object of a sentence, an entirely new semantic representation will be constructed, one that will be unrelated to previous target words, even with the presence of the same specific subject noun and verb associates in the sentence. Experiment 4 was designed to test this hypothesis. ${ }^{5}$

\section{EXPERIMENT 4}

The prediction of this experiment was that replacement of the direct object, while still retaining the two potential sources for combinatorial priming in the biased conditions, will produce a completely different sentence-level representation that will be functionally unrelated to the previously used target words. Therefore naming latencies for previously related target words should not be facili- 
tated, as compared with unrelated ones. The combinatorial model would predict that a change in the sentencelevel representation will be irrelevant, because the explicit presence of the subject noun and verb associates per se will be sufficient to prime the target words. Therefore, the results will replicate the pattern of activation observed in the biased conditions of Experiment 3 .

\section{Method}

Subjects. Forty-eight undergraduate volunteers participated. All received class credit for participation and were native English speakers with normal or corrected-to-normal vision.

Stimuli. In this experiment, the stimuli were the 72 biasing sentences used in Experiment 3, with the exception that the sentencefinal homonyms were replaced with new direct objects that (1) had no obvious relation to the original meaning of the homonym, (2) still rendered the sentence plausible, but (3) changed the semantic representation of the sentence as a whole. Sentence plausibility was agreed on by a panel of four judges. To ensure that each prime and target stimulus appeared only once for a given subject, with each subject exposed to all conditions, eight stimulus lists were constructed. In order to have balanced lists, only 32 (64 experimental trials) of the 36 homonyms from Experiment 3 were used. Note that the dominant/subordinate prime distinction was no longer valid, because all the targets were unrelated to the meaning of the newly constructed sentence primes. Table 3 contains an example of each of the conditions associated with Experiment 4 . The full set of sentence stimuli for Experiment 4 can be found in Appendix D.

Apparatus and Procedure. The apparatus and procedure are identical to those in the previous experiments.

\section{Results}

Three subjects were replaced due to a high rate of comprehension errors $(>40 \%)$ and 2 subjects were replaced due to excessive naming errors $(>10 \%)$. The subjects' mean calibrated reading speed was $274 \mathrm{msec}$ per word $(S D=37 \mathrm{msec})$. Naming errors constituted $3.6 \%$ of the data and were discarded from subsequent analyses. Comprehension accuracy was $84.4 \%$.

Mean correct naming latencies were submitted to a prime type (ambiguous, dominant bias, subordinate bias) $\times$ target dominance (dominant, subordinate) $\times$ target relatedness (related, unrelated) ANOVA for repeated measures, using both subjects $\left(F_{1}\right)$ and items $\left(F_{2}\right)$ as random factors.

No reliable main effects or interactions were observed, including the critical prime type $\times$ target dominance $X$ target relatedness interaction $\left[F_{1}(1,47)=1.27, M S_{\mathrm{e}}=\right.$ $3,075.79, p=.27 ; F_{2}(1,31)=1.31, M S_{\mathrm{e}}=3,801.92, p=$ .26]. For the dominant prime conditions, facilitation scores were $9 \mathrm{msec}$ and $-5 \mathrm{msec}$, respectively, for related dominant $(M=737 \mathrm{msec})$ and subordinate $(M=756 \mathrm{msec})$ target words, as compared with unrelated ones ( 746 and $751 \mathrm{msec}$ ). For the subordinate prime conditions, facilitation scores were $-3 \mathrm{msec}$ and $8 \mathrm{msec}$ (dominant means, related $=745 \mathrm{msec}$, unrelated $=742 \mathrm{msec}$; subordinate means, related $=729 \mathrm{msec}$, unrelated $=737 \mathrm{msec}$ ). The $S E$ associated with these null outcomes was 8.04.

\section{Discussion}

Experiment 4 provided no evidence of combinatorial intralexical priming, even in the presence of two words lexically related to the target word, such as soldier and $p a-$ trolled to the target word STATION. Apparently, both the specific subject noun and the verb only influenced naming of target words through their relationship with the evolving semantic representation of the sentence. When the sentence-level representation was related to the target words, there was evidence of priming (Experiments 1,2, and 3), but with a change in the representation, even target words associatively related to the subject noun and verb were not primed (Experiment 4). It may be argued that the results are not surprising, because the targets are related to homonyms that had been replaced. If new targets related to the new direct objects were used, an outcome similar to that in Experiment 3 might be obtained. This is undoubtedly true but is irrelevant to the issue addressed. The purpose of Experiment 4 was to determine whether combinatorial priming from the subject nouns and verbs in Experiment 3 would facilitate naming times of the target words from Experiment 3 and produce a comparable pattern of effects. It is quite clear that the same outcome does not occur when the sentence level representation is changed, even though the subject nouns, verbs, and target words remain identical. Consequently, our overall results provide evidence that priming effects can extend beyond the lexical level and that the association between words in isolation are not so efficacious when placed in context. The results of Experiment 4 are in contrast with the results and conclusions of Duffy et al. (1989).

Although not examining ambiguity resolution, Duffy et al. (1989) showed that naming latencies for sentencefinal target words were facilitated if a sentence prime contained two content words that were moderately related to the target word, regardless of context. For example, naming of the target word mustache was facilitated following both sentences (1) and (2).

1. While she talked to him the barber trimmed the mustache.

2. While talking to the barber she trimmed the mustache.

Because altering the syntax (i.e., changing the agent of the action) still led to priming of the target word, Duffy et al. (1989) argued that the source of priming must be at the lexical level. Furthermore, when only one content word was related to the target word (e.g., "The woman trimmed the mustache" or "The barber saw the mustache"), there was no evidence of facilitation. Duffy et al. (1989) concluded that a simple account of intralexical priming was insufficient and proposed that word-based priming can be best represented by a combinatorial model in which individual words can converge to prime a subsequent target word without relying on the overall meaning of the sentence. 
We submit, however, that what is claimed to be combinatorial priming can be easily interpreted within the framework of sentence-level semantic priming. First, some of the content words from Duffy et al. (1989) are only related to the target words within the context of connected discourse. For example, consider the sentence "The tree was uprooted by the hurricane." Without context, there does not appear to be any immediate, associative relationship between tree and hurricane, or uprooted and hurricane. More importantly, although the syntactic structures of sentences (1) and (2) differ, the semantic representation conveyed by each sentence is quite similar. In both examples, the barbershop scenario is invoked, the number of actors portrayed is identical, the mustache is being trimmed, and the deictic pronoun she in the second sentence implies a referent with trimming skillsanother barber or hairdresser (see also Morris, 1994, for a similar discussion). Thus, at the semantic level, the sentences convey a similar meaning, and, as a result, both sentences facilitate the naming of the target word mustache. The facilitation arose from the common semantic representation, not from combinatorial priming at the lexical level. Our argument is supported by the literature on text processing, in which it is proposed that processing of an item is facilitated as long as the word is related to the topic of the discourse (cf. Foss, 1982). Substituting the agent of the action with a general pronoun in Duffy et al. (1989) is insufficient to eliminate the semantic relationship between a target word and the sentence topic.

Further evidence that the source of priming from Duffy et al. (1989) may have been from the sentence level was reported by Morris (1994, Experiment 2). Morris modified Duffy's stimuli to incorporate a specific noun rather than a general pronoun. The specific noun was added in such a manner as to keep Duffy's original message (3, below) or to alter the message (4). Morris found that gaze duration for target words (e.g., mustache) were shorter in the original message condition but not for the altered message condition, as compared with a baseline condition. Since a gardener would not be expected to trim a mustache, Morris concluded that the results were due to priming at the sentence level; otherwise, mustache would have been primed in both conditions following the associates, barber and trimmed.

3. The gardener talked as the barber trimmed the mustache after lunch.

4. The gardener talked to the barber and trimmed the mustache after lunch.

Finally, our evidence against word-based priming is further supported by the recent work of Hess et al. (1996), which tested the assumptions of the combinatorial model. It was found that naming latencies to target words that were preceded by lexical associates in the local sentence context were not facilitated, as compared with control conditions, when the global context was unrelated to the local context. Similarly, in our Experiment 4, by changing the semantic representation, target words related to individual words making up the sentences were not facilitated.

Although Experiment 4 failed to support combinatorial priming even with two associates of the target word in short five-word sentences, an argument could be made that removal of the homonym was responsible for the null outcome. Consequently, the patterns of activation found in Experiments 1, 2, and 3 were due to the combination of verb + homonym, subject noun + homonym, and verb + subject noun + homonym, respectively, and Experiment 4 failed to show combinatorial priming because the homonym was absent. However, according to this logic, the increased priming must be due to the addition of either the verb or the subject noun but not to the homonym, which was constant across experiments. Within this framework, we contend that Experiment 4 should have produced some level of activation comparable with the magnitude of priming evidenced in Experiments 1 and $2(\sim 20 \mathrm{msec})$ because of the presence of the both associates (verb and subject noun), one of which must have been responsible for the increased priming in Experiment 3. Furthermore, we reiterate that the combinatorial model, as formulated, only requires the convergence of two lexical associates to prime a target word, regardless of the nature of the context.

Nevertheless, our point is argumentative. In order fully to defend our position against word-based priming, we conducted a fifth experiment in which we retained the specific verb and the specific subject noun, as well as the homonym in its terminal position, but in which the sentence was scrambled to eliminate the syntactic structure of the sentence, as well as the sentence-level representation. If it is the three lexical associates that are combining to prime the target words and not the sentence-level representation, the pattern of activation demonstrated in Experiment 3 (and by analogy, Experiments 1 and 2) should be replicated.

\section{EXPERIMENT 5}

Our primary prediction was that combinatorial priming cannot account for the earlier results. By scrambling the experimental stimuli, the syntactic and semantic structure of each sentence would be eliminated, and the subjects would essentially be processing lists of words. It has been demonstrated that priming effects in word lists quickly diminish with time (see, e.g., Meyer, Schvaneveldt, \& Ruddy, 1972) or with the intervention of one or more words between a priming word and a related target word (see, e.g., Foss, 1982; Gough, Alford, \& HolleyWilcox, 1981). The latter finding is compatible with Collins and Loftus (1975) and Anderson (1976), who have argued that the activation spreading through the mental lexicon must be dampened with each successive item encountered, otherwise the entire memory network would be activated with the processing of one lexical item. With the elimination of syntactic and semantic structure in the present experiment, the same lexical items that served to construct and maintain a coherent sentence-level 
representation will now represent a list structure and prevent priming effects. The processing of each scrambled item will result in activation that is transient, due to the successive presentation of syntactically inappropriate words. Without an intact syntactic structure, there will be no corresponding semantic representation to sustain activation of each word in working memory (cf. Foss, 1982). Consequently, although the noun, verb, and homonym associates of the target words are retained, the intervening items will prevent priming effects from combining and converging on the targets. Upon encountering the terminal homonym ( 0 -msec ISI), no item will have intervened prior to target presentation. Thus, only the homonym should prime the subsequent target words.

We expect that processing of the terminal homonym in word lists is akin to processing the homonym in isolation. With no sentence-level representation to influence target word activation, priming will be relegated to data-driven processes operating on the homonym by which target processing will be facilitated due to the adjacency of a related word (cf. Meyer \& Schvaneveldt, 1971). We predicted that the homonym would prime both related target words across nominally dominant and subordinate scrambled conditions but that the dominant meaning would receive more activation, due to the polarity of the homonyms (i.e., frequency-ordered activation). Our assumption is derived from Simpson and Burgess (1985), where it was demonstrated that the dominant meaning of a polarized homonym becomes available sooner than the subordinate meaning.

Again, if the combinatorial priming model is correct in assuming that priming is a direct result of lexical associations, regardless of context, the pattern of activation found in Experiment 3, in which only the contextually appropriate meanings were primed, should be replicated. The magnitude of priming should also be comparable, since the three lexical associates to the target word are identical to those in Experiment 3.

\section{Method}

Subjects. Forty-eight undergraduate volunteers participated. All received class credit for participation and were native English speakers with normal or corrected-to-normal vision.

Stimuli. The stimuli were those used in Experiment 3. Each experimental sentence was scrambled to eliminate the syntactic structure of the sentence and the corresponding semantic representation. To avoid concerns regarding lexical distance, the homonyms were kept in their terminal position. Below are two examples of the scrambled material:

The splintered the slugger bat

Patrolled soldier the the base.

Procedures for lists construction were identical to those in Experiment 3 , with the exception that 60 scrambled filler trials of differing lengths were randomly incorporated into the stimuli set to prevent the subjects from distinguishing and unscrambling the pattern of experimental stimuli.

Apparatus and Procedure. These were identical to previous experiments, with two exceptions in the procedures. First, reading rate was not calibrated for each individual subject due to the scrambled nature of the experimental stimuli. Instead, the mean reading rate of Experiment 3 was adopted ( $237 \mathrm{msec}$ per word). Second, wh-comprehension questions could not be asked, since there were no coherent sentences. Rather, for $50 \%$ of the trials, the subjects were asked yes/no recognition questions regarding whether a certain noun, verb, or homonym was present. This procedure was adopted to (1) prevent subjects from ignoring stimulus presentation and focusing only on the ambiguous word, which would inadvertently favor our prediction for frequency-ordered activation, and (2) allow an opportunity for the multiple lexical associates to combine and converge on target word naming.

\section{Results}

Three subjects were replaced due to a high rate of recognition error $(>20 \%)$, and one subject was replaced due to excessive naming errors $(>10 \%)$. Naming errors constituted $3.7 \%$ of the data and were discarded from subsequent analyses. Recognition accuracy was $92.5 \%$.

Mean correct naming latencies were submitted to a prime type $\times$ target dominance $\times$ target relatedness ANOVA for repeated measures, using both subjects $\left(F_{1}\right)$ and items $\left(F_{2}\right)$ as random variables. There was only a reliable main effect of target relatedness $\left[F_{1}(1,47)=10.98\right.$, $M S_{\mathrm{e}}=2,052.99 ; F_{2}(1,35)=2.93, M S_{\mathrm{e}}=7,062.88, p=$ .10]. The critical prime type $\times$ target dominance $\times$ target relatedness interaction was not significant $\left[F_{1}(1,47)=\right.$ $1.11, M S_{\mathrm{e}}=2,310.06, p>.29 ; F_{2}(1,35)=1.31, M S_{\mathrm{e}}=$ $3,800.38, p>.26]$.

The effect of target relatedness indicated that both dominant and subordinate meanings of the homonyms were activated, relative to unrelated targets. In order to assess whether the dominant meanings were primed to a greater extent than the subordinate meanings, we collapsed across prime type and conducted post hoc tests comparing dominant and subordinate targets with unrelated targets. Analyses showed that there was a reliable difference of $20 \mathrm{msec}$ for dominant versus unrelated targets [668 vs. $688 \mathrm{msec} ; t(47)=3.06, S E=6.53, p<.05$ ]. However, there was only a marginal difference of $10 \mathrm{msec}$ between subordinate and unrelated targets $[671$ vs. $681 ; t(47)=$ 1.62, $S E=6.63, p=.056$, one-tailed] .

\section{Discussion}

The results of Experiment 5 confirmed our initial predictions. Not only did the combination of three lexical associates fail to replicate the results of Experiment 3, when the syntactic structure and semantic representation of a sentence were eliminated, a pattern of frequencyordered activation emerged. Our finding that dominant targets received more activation than did subordinate targets was expected, due to the polarity of our homonyms, and is similar to results found for the processing of polarized homonyms in isolation (cf. Simpson \& Burgess, 1985). Consequently, both Experiments 4 and 5 provided evidence that word-based priming cannot be a viable explanation of our previous results. The point could be made that presenting the stimuli at the reading rate of Experiment 3 would further increase the difficulty of reading scrambled sentences. There are two issues here. First, reading scrambled sentences versus intact sentences probably 
would be more difficult, because of the absence of facilitory consequences of syntax and sentence semantics. Second, slowing the presentation rate to compensate for the reading difficulty would confound the comparison with Experiment 3. The intent of Experiment 5 was to clarify the nature of the comprehension processes operating during reading in Experiment 3, in the context of the stimulus words used to make up the sentences. If combinatorial priming occurred independent of syntactic connectedness and semantic cohesiveness, a comparable finding should have been found in Experiment 5 for scrambled sentences. Whether evidence for combinatorial priming would be obtained by scrambled lists of content words sans function words is an empirical question unrelated to the present research. Function words such as articles and prepositions (or infinitive markers) can be crucial for signaling the intended meaning of homonyms (e.g., the watch vs. to watch), as well as for establishing referential coherence in texts (Gernsbacher, 1990). As such, the presence of function words provides additional sources of constraint on lexical ambiguity resolution. To arbitrarily exclude these constituents of the sentences in order to determine whether combinatorial priming would occur in their absence would be inappropriate and would not inform us regarding the possibility of combinatorial priming in sentence contexts. It was essential that we examine the priming that occurs from the full set of stimulus words that produced the earlier priming effects.

Additional evidence against word-based priming has been provided by other researchers (e.g., Dopkins et al., 1992; Foss, 1982; Foss \& Speer, 1991; O’Seaghdha, 1989, 1991; Simpson, Peterson, Casteel, \& Burgess, 1989). In particular, Foss demonstrated that detection of a phoneme was facilitated in related versus neutral sentence contexts, but this difference was eliminated when the contexts were scrambled, even though the scrambled related context contained two associates preceding the targets and the adjacency of the associates and targets was maintained.

For the present research, we argue that lexical-level priming of a target word is operative only when there is no coherent context and is restricted to the contiguous final word and target. Such priming effects are also transient and have less magnitude, as compared with priming in connected discourse. Intervention of one or more lexical items unrelated to the critical prime word diminishes priming, as was demonstrated by Gough et al. (1981), Foss (1982), and the results of Experiment 5. It is noteworthy that the definition of relatedness of an intervening word rests on whether a coherent representation can be constructed. A coherent context and its scrambled version contain identical constituents, yet intervening words between two lexical associates are considered to be related in a coherent context and unrelated in the scrambled version. Consequently, it is not simply a matter of intervening words preventing priming but, instead, a matter of constructing a semantic representation to sustain meaning activation. In scrambled lists of words, no discourse topic can be constructed. Therefore, activation of mean- ings related to any particular word will diminish quickly. In well-formed discourse, however, a topic is constructed and maintained with each successive word, resulting in an activated representation that is sustained, which will continue to prime related words that are further down the processing stream.

In this experiment, in which the context was scrambled, there was multiple activation due to the terminal homonym, but there was no combining of associates to converge on target priming. That is, we showed that, regardless of whether the associates preceding the homonym were in the dominant or subordinate scrambled conditions, priming was greater for target words related to the dominant sense of the homonym than for those related to the subordinate sense. In order for the combinatorial model of priming to be a viable explanation of our earlier results, the results of Experiment 5 would had to have shown priming of only the appropriate meanings in dominant and subordinate scrambled contexts as well as replicate the magnitude of priming demonstrated in Experiment 3, since the identical constituents were used. Failure to replicate the pattern of activation found in Experiments 1, 2 , and 3 and the magnitude of activation together support our conclusion that priming effects extend beyond simple word-based priming. Apparently, word-based priming between lexical associates is minimized in connected discourse. Words that are associatively related in isolation may not be so when embedded in context.

\section{EXPERIMENT 6}

A final alternative interpretation of the present research concerns the exposure duration of the homonym. Perhaps by allowing the subjects to determine their own presentation rate (Experiments 1-4), multiple meanings of the homonym may have been activated initially, followed by subsequent selection of an appropriate meaning before the target word had been presented. We contend, however, that individually calibrated reading speed is a preferred method of presentation for the following reasons. First, the subjects were instructed to read at their normal rate and, thus, the rate of reading is more ecologically valid. Second, calibrated reading speed provides a better estimate of the ISI than would a predetermined rate of presentation. By using a standard reading rate, the ISI would be long for fast readers, and slow readers may not have an opportunity to finish reading the terminal homonym before the target word is presented. Thus, it would appear that using a predetermined presentation rate would do more to contaminate and compromise the results than using calibrated reading rates for each individual. Finally, a literature search indicates that our reading rates are well within the range of gaze durations measured by eye tracking (around $250-300 \mathrm{msec}$ ) as well as of the experimenter controlled rates employed in most research involving lexical processing. For example, presentation rates have been found to range from $250 \mathrm{msec}$ per word (Duffy et al., 1989); $263 \mathrm{msec}$ (Paul et al., 1992; averaged across three 
experiments); $300 \mathrm{msec}$ (Simpson \& Krueger, 1991; Simpson et al., 1989); 333 msec (Till, Mross, \& Kintsch, 1988); $400 \mathrm{msec}$ (O'Seaghdha, 1989); up to $500 \mathrm{msec}$ per word (Stanovich \& West, 1983). Given these presentation rates, we contend that the calibrated reading rate is justified, considering that the average reading rate across the critical Experiments 1, 2, and 3 was $265 \mathrm{msec}$ per word.

If it is the case that the average $265-\mathrm{msec}$ stimulus onset aynchrony (SOA) of Experiments 1, 2, and 3 was of sufficient duration for selection processes to have occurred, target words related to both senses of the homonym should be primed, regardless of contextual bias, when the sentence-final homonym is presented for $80 \mathrm{msec}$. However, it was predicted that, even with an SOA of $80 \mathrm{msec}$, only the contextually appropriate target words would be facilitated following sentences rated as strongly biased. Only after sentences rated as ambiguous would both senses of the homonyms be primed.

\section{Method}

Subjects. The subjects were 48 undergraduates from an introductory psychology course. All received class credit for participation and were native English speakers with normal or corrected-tonormal vision.

Stimuli. The stimuli used were those from Experiment 3, with the addition of 36 ambiguous sentences from Experiment 2 (using the same homonyms), for purposes of comparison.

Apparatus and Procedure. These were identical to those in Experiment 3, with one exception in the procedure. For this experiment, the subjects' normal reading rate was calibrated as in previous experiments. The established reading rate was subsequently used in the experimental trials, except for the sentence-final homonym, which was presented for $80 \mathrm{msec}$. Immediately after the offset of the homonym ( 0 -msec ISI), the target word was presented.

\section{Results}

Two subjects were replaced due to a high rate of comprehension errors $(>40 \%)$, and two subjects were replaced due to excessive naming errors $(>10 \%)$. The subjects' average calibrated reading speed was $264 \mathrm{msec}$ per word $(S D=25 \mathrm{msec})$. Naming errors constituted only $3.9 \%$ of the total data and were excluded from subsequent analyses. Comprehension accuracy was $83.1 \%$.

Mean correct naming latencies were submitted to a prime type $\times$ target dominance $\times$ target relatedness ANOVA for repeated measures, using both subjects $\left(F_{1}\right)$ and items $\left(F_{2}\right)$ as random variables. All effects reported are significant at $p<.05$, unless otherwise indicated. Mean latencies, standard errors, percent errors, and the magnitude of priming are shown in Table 4.

An examination of Table 4 indicates that the naming latencies for target words following both dominant and subordinate sentences were facilitated when these targets were appropriate but not when inappropriate, as compared with unrelated conditions. Under the ambiguous prime condition, however, both dominant and subordinate target words were facilitated, as compared with unrelated conditions. This description is supported by the following statistical outcomes.

There was a reliable effect of target relatedness $\left[F_{1}(1,47)=12.70, M S_{\mathrm{e}}=2,671.56 ; F_{2}(1,35)=3.88, M S_{\mathrm{e}}=\right.$
$7,917.83, p=.06]$. The main effect was qualified by the interaction of prime type $\times$ target dominance $\times$ target relatedness $\left[F_{1}(2,94)=4.36, M S_{\mathrm{e}}=2,408.35 ; F_{2}(2,70)=\right.$ $\left.2.2, M S_{\mathrm{e}}=6,222.06, p=.12\right]$. No other main effects or interactions were significant.

The above interaction was examined further by evaluating target dominance $\times$ target relatedness for each prime type separately. For the dominant prime condition, there was a reliable effect of target relatedness $\left[F_{1}(1,47)=4.73\right.$, $M S_{\mathrm{e}}=2,424.87$; but $F_{2}(1,35)=0.87, M S_{\mathrm{e}}=6,838.09$, $p=.36]$. This effect was qualified by the interaction of target dominance $\times$ target relatedness $\left[F_{1}(1,47)=5.71\right.$, $M S_{\mathrm{e}}=2,174.84 ; F_{2}(1,35)=2.00, M S_{\mathrm{e}}=6,222.06, p=$ .17]. As Table 4 indicates, responses to dominant targets were facilitated following dominant primes, relative to the unrelated condition $[t(47)=3.19, p<.002]$. Responses to subordinate targets showed no evidence of facilitation, relative to the unrelated condition $[t(47)=0.07, p>.47]$.

Results for the subordinate prime condition showed an opposite pattern. There was only an interaction of target dominance $\times$ target relatedness $\left[F_{1}(1,47)=4.00, M S_{\mathrm{e}}=\right.$ $2,182.32, p=.05 ; F_{2}(1,35)=2.17, M S_{\mathrm{e}}=6,681.61, p=$ .15]. As shown in Table 4, responses to subordinate targets were facilitated following subordinate primes, relative to the unrelated condition $[t(47)=2.39, p<.02]$. Conversely, responses to dominant targets were not facilitated $[t(47)=0.10, p>.45]$.

Finally, an analysis of the ambiguous prime condition showed only an effect of target relatedness $\left[F_{1}(1,47)=\right.$ $5.17, M S_{\mathrm{e}}=2,408.35 ;$ but $F_{2}(1,35)=1.44, M S_{\mathrm{e}}=$ $6,222.06, p=.24]$. The effect of target relatedness indicated that responses to targets related to both meanings of the homonym were facilitated, relative to unrelated targets.

\section{Discussion}

The results of Experiment 6 argue against the interpretation that the outcomes of Experiments 1, 2, and 3 were due to selection processes. Priming of target words related to both senses of the homonym was evident only in the ambiguous condition, whereas in the biased conditions only one sense was primed. This conclusion is further supported by the research of Paul et al. (1992, Experiment 3 ), in which evidence was found for activation of contextually appropriate targets, even when the sentencefinal homonyms were presented for $50 \mathrm{msec}$. Finally, the validity of word-by-word reading measures and naming methodology has been upheld by recent research. Altarriba, Kroll, Sholl, and Rayner (1996) employed eyetracking methodology and a naming task, using an RSVP mode of presentation in separate experiments. It was demonstrated that the pattern of data for first fixations (generally regarded as reflecting initial activation) converged with that for naming latencies.

\section{GENERAL DISCUSSION}

Our primary contributions from the present research are (1) demonstrating that strength of context is an important parameter in ambiguity resolution-the pattern 
of activation obtained for a homonym can immediately depend on the strength of the biasing context, (2) isolating the sources of constraint that render a context strong or ambiguous, (3) providing evidence that the convergence of multiple constraints can further influence word meaning activation, and (4) establishing that priming effects extend beyond simple word-based associations. Strength of context was determined by systematic manipulation of the specificity of lexical categories making up a sentence. Experiments 1 and 2 provided evidence that the specific verbs and subject nouns of simple sentences can provide immediate sources of constraint on lexical ambiguity resolution. Experiment 3 showed that, when multiple constraints were combined, there was a relative increase in priming of contextually appropriate target words. The combination of multiple constraints must have enriched the sentence representations such that there was more featural overlap between the contexts and the related target words. Experiments 4 and 5 indicated that lexically based constraints only played a significant role as each contributed to the evolving sentence-level representation. When the semantic representation of the sentence was unrelated to the targets (Experiment 4) or when there was no sentence-level representation (Experiment 5), these sources of constraint were not influential in determining word meaning activation. Apparently, these constraints only assert their effects in connected discourse. Finally, Experiment 6 provided evidence against the argument that our previous results reflected selection processes. The pattern of activation found in Experiments 1,2, and 3 was replicated even with a brief exposure duration of the homonym.

It is noteworthy that our patterns of meaning activation in subordinate biasing conditions conflict with results found by Rayner and his colleagues (e.g., Dopkins et al., 1992; Duffy et al., 1988; Rayner \& Duffy, 1986; Rayner et al., 1994). According to their reordered access model of ambiguity resolution (Duffy et al., 1988), if a homonym is balanced (having equally likely meanings), context can activate the contextually appropriate meaning. However, if the homonym is polarized, only the dominant meaning is activated in dominant biased contexts, whereas both dominant and subordinate meanings are activated in subordinate biased contexts. Indeed, Rayner and colleagues have found eye fixation time on a homonym to be longer than on a control word when the context biases the subordinate sense but not the dominant sense of the ambiguity. This has been termed a $s u b$ ordinate bias effect. The increased processing time on the homonym in subordinate context is inferred to reflect activation of both senses of the ambiguity, the subordinate sense due to context and the dominant sense due to meaning frequency. In our research, the results clearly provided no evidence that the dominant sense was activated following strong subordinate contexts. There are two possible reasons for the discrepancies between the results reported by Rayner and his colleagues and the results reported here: (1) The homonym corpus used in our ex- periments was not sufficiently polarized, or (2) the priming stimuli used by Rayner et al. were not strong enough.

With regard to the first possibility, the polarity of our homonym corpus was .76, whereas those used by Rayner and colleagues were around .91. It may be the case that there was a sufficient number of balanced homonyms in our corpus to provide our pattern of results. However, when we eliminated the balanced items from the set of homonyms, we obtained the same pattern of activation with a corpus polarity of .84 (see note 4 ). We doubt that an .84 corpus versus a .91 corpus of polarized homonyms is sufficient to explain the empirical differences. Instead, we offer a second possibility. It is our speculation that Rayner's findings were due to insufficient contextual constraints. Although Rayner does examine the type of contextual bias (i.e., dominant or subordinate), the parameter of context strength is ignored. With no empirical assessment of context strength, it may be the case that Rayner's contexts, although biasing toward a subordinate sense, are not sufficiently constraining of the ambiguity to preclude activation of the dominant meanings of polarized homonyms (i.e., the contexts used were weakly constraining). For example, consider the following biasing contexts:

(1a) "If you are concerned about having made an error, the table..."

(1b) "Although they were scattered through the house, the glasses..."

Both sentences 1a (from Duffy et al., 1988) and $1 \mathrm{~b}$ (from Dopkins et al., 1992) are not sufficiently biased toward the subordinate meaning (e.g., table of numbers, drinking glasses) at the point of the ambiguity. The dominant meanings are compatible in these sentences (e.g., the table in the corner has a calculator on it, the glasses were still in their leather cases).

Recent research by Kellas, Martin, Yehling, Herman, and $\mathrm{Vu}$ (1995) provides support for our interpretation of Rayner and colleagues' results. Using empirically rated stimuli in a self-paced reading task, Kellas et al. (Experiment 1) found processing of polarized homonyms to be longer in weak subordinate than in weak dominant contexts. However, in strong dominant and subordinate biased contexts, processing times of the homonyms were equal. In order to more directly evaluate what meanings were activated, Kellas et al. (Experiment 2) examined naming latencies for target words concurrent with self-paced reading. Target naming latencies revealed that, when the contexts were weakly biased, only the dominant meaning was activated following dominant contexts but both meanings were activated following subordinate contexts. However, when the contexts were strongly biased, only the appropriate meaning was activated following both dominant and subordinate conditions. Thus, Kellas et al. showed that the subordinate bias effect can be replicated or eliminated, depending on the strength of context.

A possible objection against the interpretation of our present data would be that our results were due to com- 
binatorial intralexical priming. Although this argument is noteworthy, it cannot explain the results of Experiments 4 and 5. Perhaps more clarity is needed in defining what is meant by words acting in combination but without being considered as connected discourse. We contend that, as words combine, some approximation to connected discourse invariably emerges, especially if the combination preserves syntactic constraints (i.e., the words are not scrambled). The problem that emerges is distinguishing where intralexical priming ends and where sentence context effects begin. When a target word is primed by a related word in context, it is difficult to differentiate whether the priming is intralexical or sentence level. Foss (1982) demonstrated that a related word can prime a target word that was further down the processing stream, but only if a coherent semantic representation can be constructed. Priming of the target word was eliminated when the context was scrambled. We reiterate that it is not the intervention of unrelated words per se that inhibits priming: Lexical associates in unscrambled contexts are often separated by words that could be considered unrelated without reference to the overall discourse, and a coherent context and its scrambled version are composed of identical lexical constituents. Instead, it is the intervention of syntactically unexpected words that prohibits construction of a semantic representation and prevents priming of separated lexical associates. The (un)relatedness of a word with its context will depend on the satisfaction of syntactic constraints.

Similar to Foss (1982), we took a straightforward approach in separating intralexical from sentence-level priming. We retained the multiple lexical associates of the target words and changed the semantic representation of the sentence (Experiment 4 ) or eliminated the sentencelevel representation by scrambling the constituents (Experiment 5) and showed that word-based priming cannot account for the results of Experiments 1, 2, and 3. The combinatorial model of intralexical priming (Duffy et al., 1989), as formulated, would have to predict a replication of our earlier results, because the model proposes that it is the explicit presence of lexical constituents and not the sentence-level representation that is priming the target words. Clearly, in Experiments 4 and 5, some magnitude of priming of the contextually appropriate target words should have emerged in the explicit presence of the subject noun and verb (and homonym). Our research does, however, suggest that word-based priming can occur when a homonym is presented contiguously with the target. Still, this level of priming cannot explain the context effects evident from connected discourse. Consider also that, when there is a sentence-level representation, one associate of the homonym in isolation is rendered inappropriate if the representation is biased toward the alternative meaning of the embedded homonym. These inappropriate target words do not receive activation, or minimally do so. On the other hand, when there is no sentence-level representation (e.g., as in scrambled contexts), both the dominant and subordinate target words are appropriate associates of the terminal homonyms. and both receive activation as they would in isolation (i.e., in order of frequency).

In view of the above, a sentence-level interpretation seems quite compelling. The pattern of meaning activation obtained for a homonym will depend on the strength of context. When the context is strongly biased, the contextually appropriate meaning of a homonym will be constrained. However, when the contextual constraints are relaxed, multiple meanings of a homonym will be supported. Only target words sharing features with those activated by the context are facilitated, whereas words that are inappropriate (or unrelated) to the context will not show facilitation, even if these target words share features with the homonym in isolation. From the body of evidence provided by the present research, we offer a contextsensitive model of lexical ambiguity resolution. Empirically, the context-sensitive position serves to reconcile the lexical ambiguity literature by accounting for the different patterns of meaning activation that have been observed. We submit that stimulus analysis of a homonym leads to the computation of multiple meanings, whose activation levels are maintained when a context is ambiguous (cf. Experiments 1 and 2). The computed activation levels may emerge as ordered activation in which the dominant meaning receives more activation due to meaning frequency if the homonym is polarized. However, a sufficiently strong context will constrain activation to only one meaning and inhibit the alternative meanings. This includes activation of only the subordinate sense of a homonym, provided the context is of sufficient strength to inhibit meaning frequency effects, as is demonstrated here.

In conclusion, the results of the present series of experiments have highlighted the contribution of lexicallevel constraints to sentence-level representations. What underlies strength-of-context effects as reported by Simpson and Krueger (1991) and others (e.g., Paul et al., 1992; Tabossi et al., 1987) can be understood in terms of the lexical semantics of grammatical categories. Judicious selection of fillers for these categories will directly determine subjects' ratings of overall strength of context and the pattern of meaning activation of ambiguous words. Future research needs to address how categories other than the verb and subject noun may constrain sentencelevel representations. For example, by replacing a simple preposition, the semantic representation of "He was hit with a club" is completely different from "He was hit in a club." Such empirical demonstrations would further support our position for a context-sensitive model of language processing.

\section{REFERENCES}

Altarriba, J., Kroll, J. F., Sholl. A., \& Rayner, K. (1996). The in fluence of lexical and conceptual constraints on reading mixedlanguage sentences: Evidence from eye fixations and naming times Memory \& Cognition, 24, 477-492.

Anderson, J. A. (1976). Language, memory, and thought. Hillsdale, NJ: Erlbaum.

Collins, A. M., \& Loftus, E. F. (1975). A spreading activation the ory of semantic processing. Psichological Review, 82, 407-428. 
Dopkins, S., Morris, R. K., \& RaYNeR, K. (1992). Lexical ambiguity and eye fixation in reading: A test of competing models of lexical ambiguity resolution. Journal of Memory \& Language, 31, 461-476.

Duffy, S. A., Henderson, J. M., \& Morris, R. K. (1989). Semantic facilitation of lexical access during sentence processing. Journal of Experimental Psychology: Learning, Memory, \& Cognition, 15, 791-801.

DUFFY, S. A., MORRIS, R. K., \& RAYNER, K. (1988), Lexical ambiguity and fixation times in reading. Journal of Memory \& Language, 27, 429-446.

FODOR, J. A. (1983). Modularity of mind. Cambridge, MA: MIT Press FORSTER, K. I. (1979). Levels of processing and the structure of the language processor. In W. E. Cooper \& E. Walker (Eds.), Sentence processing: Psycholinguistic studies presented to Merrill Garrett (pp. 27-85). Hillsdale, NJ: Erlbaum.

Foss, D. J. (1982). A discourse on semantic priming. Cognitive Psychology, 14, 590-607.

Foss, D. J., \& SPEER. S. R. (1991). Global and local context effects in sentence processing. In R. Hoffman \& D. Palermo (Eds.), Cognition and the symbolic processes: Vol. III. Applied and ecological perspectives (pp. 115-139). Hillsdale, NJ: Erlbaum.

Garnham, A. (1985). Psycholinguistics: Central topics. Cambridge Cambridge University Press.

GernsBaCher, M. A. (1990). Language comprehension as structure building. Hillsdale, $\mathrm{NJ}$ : Erlbaum.

Gough, P. B., Alford, J. A., JR., \& Holley-Wilcox, P. (1981). Words and contexts. In O. J. L. Tzeng \& H. Singer (Eds.), Perception of print: Reading research in experimental psychology (pp. 85-102). Hillsdale, NJ: Erlbaum.

Hess, D. J., Foss, J. F., \& Carroll, P. (1996). Effects of global and local context on lexical processing during language comprehension. Journal of Experimental Psychology: General, 124, 62-82.

Hogaboam, T. W., \& Perfetti, C. A. (1975). Lexical ambiguity and sentence comprehension. Journal of Verbal Learning \& Verbal Behavior, 14, 265-274.

JUST, M. A., \& CARPENTER, P. A. (1987). The psychology of reading and language comprehension. Newton, MA: Allyn \& Bacon.

Just, M. A., Carpenter, P. A., \& Woolley, J. D. (1982). Paradigms and processes in reading comprehension. Journal of Experimental Psychology: General, 111, 228-238.

Kawamoto, A. H. (1993). Nonlinear dynamics in the resolution of lexical ambiguity: A parallel distributed processing account. Journal of Memory \& Language, 32, 474-516.

Kellas, G., Martin, C., Yehling, K., Herman, R., \& Vu, H. (1995, November). Contextual strength as a determinant of the subordinate bias effect. Poster presented at the 36th Annual Meeting of the Psychonomic Society, Los Angeles.

Kellas, G., Paul, S. T., Martin, M., \& Simpson, G. B. (1991). Contextual feature activation and meaning access. In G. B. Simpson (Ed.), Understanding word and sentence (pp. 47-71). Amsterdam: Elsevier.

KINTSCH, W. (1974). The representation of meaning in memory. Hillsdale, NJ: Erlbaum

KuČERA, H., \& FrANCIS, W. (1967). Computational analysis of presentday American English. Providence, RI: Brown University Press.

MacDonald, M. (1993). The interaction of lexical and syntactic ambiguity. Journal of Memory \& Language, 32, 692-715.

MacDonald, M., Pearlmutter, N.. \& Seidenberg, M. (1994). Lexical nature of syntactic ambiguity resolution. Psychological Review, 101. 676-703.

MarsLEN-Wilson, W., \& TYleR, L. K. (1987). Against modularity. In J. Garfield (Ed.), Modularity in knowledge representation and natural-language understanding (pp. 37-62). Cambridge, MA: MIT Press

Massaro, D., Taylor, G., Venezky, R, Jastrzembski, J., \& LuCas, P. (1980). Letter and word perception: The role of orthographic structure and visual processing in reading. Amsterdam: North-Holland.

MCClelland, J. L. (1987). The case for interactionism in language processing. In M. Coltheart (Ed.), Attention and performance XII: The psychology of reading (pp. 3-36). Hillsdale, NJ: Erlbaum.

Meyer, D. E., \& Schvaneveldt, R. W. (1971). Facilitation in recognizing pairs of words: Evidence of a dependence between retrieval operations. Journal of Experimental Psvchologv, 90, 227-234.
Meyer, D. E., Schvaneveldt, R. W., \& Ruddy, M. G. (1972, November). Activation of lexical memory. Paper presented at the Annual Meeting of the Psychonomic Society, St. Louis.

MORRIs, R. K. (1994). Lexical and message-level sentence context effects on fixation times in reading. Journal of Experimental Psychology: Learning, Memory, \& Cognition, 20, 92-103.

Nelson, D. L., McEvoy, C. L., Walling, J. R., \& WheEler, J. W., JR. (1980). The University of South Florida homograph norms. Behavior Research Methods \& Instrumentation, 12, 16-37.

ONIFER, W., \& SWINNEY, D. A. (1981). Accessing lexical ambiguities during sentence comprehension: Effects of frequency of meaning and contextual bias. Memory \& Cognition, 9, 225-236.

O'SEAGHDhA, P. G. (1989). The dependence of lexical relatedness ef fects on syntactic connectedness. Journal of Experimental Psychology: Learning, Memory, \& Cognition, 15, 73-87.

O'SEAGHDha, P. G. (1991). A perspective on sentence context research. In G. B. Simpson (Ed.), Understanding word and sentence (pp. 73-96). Amsterdam: Elsevier.

Paul, S. T., Kellas, G., Martin, M., \& Clark, M. B. (1992). Influence of contextual features on the activation of ambiguous word meanings. Journal of Experimental Psychology: Learning, Memory. \& Cognition, 18, 703-717.

RaYNER, K., \& DUFFY, S. A. (1986). Lexical complexity and fixation times in reading: Effects of word frequency, verb complexity, and lexical ambiguity. Memory \& Cognition, 14, 191-201.

Rayner, K., \& Frazier, L. (1989). Selection mechanisms in reading lexically ambiguous words. Journal of Experimental Psychology. Learning, Memory, \& Cognition, 15, 779-790.

Rayner, K., PACht, J. M., \& DufFy, S. A. (1994). Effects of prior encounter and global discourse bias on the processing of lexically ambiguous words: Evidence from eye fixations. Journal of Memory \& Language, 33, 527-544.

SANFORD, A. J., \& GaRrod, S. C. (1981). Understanding written language. New York: Wiley.

SChWANENFlugel, P. J., \& LaCount, K. (1988). Semantic relatedness and the scope of facilitation for upcoming words in sentences. Journal of Experimental Psychology: Learning, Memory, \& Cognition, $14,344-354$

SChwanenflugel, P. J., \& Shoben, E. J. (1985). The influence of sentence constraint on the scope of facilitation for upcoming words. Journal of Memory \& Language, 24, 232-252.

Seidenberg, M. S., Tanenhaus, M. K.. Leiman, J. M., \& Bienkowski, M. (1982). Automatic access of the meanings of ambiguous words in context: Some limitations of knowledge-based processing. Cognitive Psychology, 14, 489-537.

SrMPSON, G. B. (1981). Meaning dominance and semantic context in the processing of lexical ambiguity. Journal of Verbal Learning \& Verbal Behavior, 20, 120-136.

Simpson, G. B. (1984). Lexical ambiguity and its role in models of word recognition. Psychological Bulletin, 96, 316-340.

SIMPSON, G. B. (1994). Context and the processing of ambiguous words. In M. A. Gernsbacher (Ed.), Handbook of psycholinguistics (pp. 359-374). San Diego: Academic Press.

Simpson, G. B., \& BURGESs, C. (1985). Activation and selection processes in the recognition of ambiguous words. Journal of Experimental Psychology: Human Perception \& Performance, 11, 28-39.

Simpson, G. B., \& KRUEGER, M. A. (1991). Selective access of homograph meanings in sentence context. Journal of Memory \& Language, 30, 627-643

Simpson, G. B., Peterson, R. R., Casteel, M. A., \& Burgess, C. (1989). Lexical and sentence context effects in word recognition Journal of Experimental Psychology: Learning, Memory, \& Cognition, 15, 88-97.

Stanovich, K. E., \& West, R. F. (1983). On priming by a sentence context. Journal of Experimental Psychology: General, 112, 1-36.

Tabossi, P., Colombo, L., \& Job. R. (1987). Accessing lexical ambiguity: Effects of context and dominance. Psychological Research, 49, 161-167

TABossi, P., \& ZARDON, F. (1993). Processing ambiguous words in context. Journal of Memory \& Language, 32, 359-372.

Tanenhaus, M. K., Leiman, J. M., \& Seidenberg, M. S. (1979). Evidence for multiple stages in the processing of ambiguous words in 
syntactic contexts. Journal of Verbal Learning \& Verbal Behavior 18, 427-440.

Taraban, R., \& McClelland, J. L. (1988). Constituent attachment and thematic role assignment in sentence processing: Influences of content-based expectations. Journal of Memory \& Language, 27, 597632.

Till, R. E., Mross, E. F., \& KINTSCH, W. (1988). Time course of priming for associate and inference words in a discourse context. Memory \& Cognition, 16, 283-298.

Trueswell, J., \& Tanenhaus, M. (1994). Toward a lexicalist approach to syntactic ambiguity resolution. In C. Clifton, Jr., L. Frazier, \& K. Rayner (Eds.), Perspectives on sentence processing (pp. 155179). Hillsdale, NJ: Erlbaum.

Twilley, L. C., Dixon, P., Taylor, D., \& Clark, K. (1994). University of Alberta norms of relative meaning frequency for 566 homographs. Memory \& Cognition, 22, 111-126.

Van Petten, C., \& Kutas, M. (1987). Ambiguous words in context: An event-related potential analysis of the time course of meaning activation. Journal of Memory \& Language, 26, 188-208.

\section{NOTES}

1. The procedure for defining polarity was adopted from Rayner and Frazier (1989), in which probability values were based only on the two alternatives used in the study, Responses other than the two alterna- tives were eliminated, such that probability computation summed to 1.00 in all cases.

2 . There were only two exceptions that varied from the subject, verb, direct object format-one in Experiment $I$ and the other in Experiment 2. The constructed sentences for both of these exceptions were in the form of subject, verb, prepositional phrase (i.e., "He came from the bank" in Experiment 1 and "The man prepared for the fall" in Experiment 2 ).

3. Ad hoc examination of the corpus revealed that two thirds of the homonyms were highly polarized (range, $.71-1.00, M=.84$ ). Analyses of this subset revealed the same interaction of prime type $\times$ target type $X$ target dominance $\left[F_{1}(2,94)=3.65, p<.03 ; F_{2}(2,124)=2.71, p=.07\right]$. Also, two thirds of the homonym corpus in Experiment 2 were highly polarized (range, $.70-1.00, M=.85$ ) and produced a significant interaction as well $\left[F_{1}(2,94)=5.13, p<.008 ; F_{2}(2,126)=2.79, p=.065\right]$.

4. Similarly, formal error analyses were not conducted for Experiments 3 and 6 . Again, however, the pattern of results from these experiments (Table 4) showed no evidence for a speed-accuracy tradeoff $(r=+.35$ and $r=+.18$, respectively)

5 . The concern for simple intralexical priming warranted two control experiments examining word-based priming from the verbs of Experiment 1 and subject nouns of Experiment 2 . Neither study provided any evidence of intralexical priming by subjects $\left[F_{1}(1,47)=1.60\right.$ and 0.50$]$ or by items $\left[F_{2}(1,95)=1.90\right.$ and 0.13$]$ analyses. However, for brevity, we will only report Experiment 4 concerning the more elaborate combinatorial intralexical priming, which subsumes the issue of simple priming. 


\section{APPENDIX A}

Sentence Stimuli Employed in Experiment 1: Verb Manipulation

The structure for all of the sentence stimuli, indicated by the superscripts in the first sentence, was as follows: averb used for ambiguous biased sentence, ${ }^{b}$ verb used for dominant biased sentence, ${ }^{c}$ verb used for subordinate biased sentence, and ${ }^{d}$ ambiguous word serving as direct object.

1. He cleaned ${ }^{a}$ (massaged) ${ }^{b}$ (discharged) ${ }^{c}$ his arms. ${ }^{d}$

2. She watched (inflated) (catered) the ball.

3. He came (embezzled) (fished) from the bank.

4. He painted (opened) (bent) the bar.

5. She investigated (heard) (peeled) the bark.

6. He approached (stole) (patrolled) the base.

7. He located (splintered) (wounded) the bat.

8. She lowered (reinforced) (focused) the beam.

9. She described (called) (climbed) the bluff.

10. He divided (nailed) (appointed) the board.

11. She expected (patched) (enjoyed) the break.

12. He spotted (poisoned) (planted) a bug.

13. He delivered (carved) (harvested) the cane.

14. She manufactured (wore) (unscrewed) the cap.

15. She exchanged (shuffled) (mailed) the cards.

16. He finished (chugged) (defended) a case.

17. She hated (autographed) (directed) the cast.

18. He damaged (occupied) (magnified) the cell.

19. She accepted (pocketed) (implemented) the change.

20. He reviewed (billed) (commanded) the charge.

21. She displayed (cultivated) (engraved) her charm.

22. She knew (totaled) (kissed) the count.

23. He forgot (memorized) (jilted) the date.

24. She searched (mopped) (sorted) the deck.

25. They feared (executed) (raided) the dive.

26. She saved (sweetened) (spent) the dough.

27. He approved (dodged) (typed) the draft.

28. She anticipated (broke) (preferred) the fall.

29. He hit (unplugged) (thanked) the fan.

30. He checked (plowed) (defeated) the field.

31. She scrutinized (outlined) (multiplied) the figure.

32. She needed (reorganized) (dulled) the file.

33. She held (wrinkled) (thrust) the foil.

34. He contained (siphoned) (pressurized) the gas.

35. She liked (drank) (played) gin.

36. She salvaged (landscaped) (percolated) the grounds.

37. She ignored (predicted) (answered) the hail.

38. He despised (sliced) (hired) the ham.

39. She hid (dried) (dealt) her hand.

40. He grabbed (sounded) (grew) a horn.

41. She carried (melted) (disconnected) the iron.

42. He exaggerated (attempted) (craved) the kick.

43. She fed (dressed) (sheared) the kid.

44. She copied (forwarded) (capitalized) the letter.

45. She transported (recycled) (wormed) the litter.

46. He cut (picked) (combed) the lock.

47. He used (chopped) (computed) the log.

48. He requested (started) (saluted) the major.
49. She chipped (sculpted) (rolled) the marble.

50. They found (were) (lit) a match.

51. He blamed (recorded) (courted) the miss.

52. She discarded (cultured) (cast) the mold.

53. He showed (tangled) (tabulated) the net.

54. She changed (crumpled) (hummed) the note.

55. He refused (tuned) (implanted) the organ.

56. He raised (unzipped) (led) the pack.

57. He received (intercepted) (borrowed) the pass.

58. She emptied (misplaced) (shoveled) the pen.

59. He mounted (built) (cooked) the perch.

60. He alternated (tossed) (increased) the pitch.

61. He bumped (spilled) (introduced) the pitcher.

62. He burned (smuggled) (scrubbed) the pot.

63. She studied (questioned) (dilated) the pupil.

64. She produced (strung) (caused) the racket.

65. She adjusted (heated) (calculated) the range.

66. She modified (flaunted) (silenced) the ring.

67. She suggested (practiced) (baked) the roll.

68. He examined (aligned) (assassinated) the ruler.

69. She installed (shut) (brightened) the screen.

70. She returned (trained) (licked) the seal.

71. She switched (ground) (scheduled) the shift.

72. She wanted (ran) (forecasted) the shower.

73. He stored (loaded) (prescribed) the sling.

74. He removed (squished) (fired) the slug.

75. She touched (stitched) (fried) the sole.

76. She offered (purchased) (trumped) the spade.

77. He advertised (congratulated) (rewired) the speaker.

78. She smoothed (refrigerated) (ironed) the spread.

79. She missed (enjoyed) (compressed) the spring.

80. She manipulated (measured) (married) a square.

81. He discussed (disinfected) (contrived) the stall.

82. He discovered (orbited) (entertained) a star.

83. He sold (liquidated) (slaughtered) his stock.

84. She surrendered (mortgaged) (consumed) her store.

85. He chewed (bailed) (sucked) the straw.

86. He overruled (pitched) (mediated) the strike.

87. He presented (modeled) (filed) the suit.

88. She tried (flipped) (advised) the switch.

89. He noticed (quieted) (killed) the tick.

90. She included (loosened) (scored) the tie.

91. She considered (earned) (followed) the tip.

92. He prepared (buttered) (proposed) the toast.

93. He scratched (closed) (curled) his trunk.

94. He repaired (torpedoed) (ruptured) the vessel.

95. He pictured (attended) (surfed) the wake.

96. He took (set) (stood) the watch. 


\section{APPENDIX B}

Sentence Stimuli Employed in Experiment 2: Subject Noun Manipulation

The structure for all of the sentence stimuli, indicated by the superscripts in the first sentence, was as follows: asubject noun used for ambiguous biased sentence, ${ }^{b}$ subject noun used for dominant biased sentence, ${ }^{c}$ subject noun used for subordinate biased sentence, and dambiguous word serving as direct object.

1. The man ${ }^{\mathrm{a}}$ (physician $)^{\mathrm{b}}(\text { marksman })^{\mathrm{c}}$ cleaned his arms. ${ }^{\mathrm{d}}$

2. The woman (juggler) (ballerina) imagined the ball.

3. The man came (robber) (alligator) from the bank.

4. The woman (collie) (botanist) investigated the bark.

5. The man (runner) (soldier) approached the base.

6. The man (slugger) (biologist) located the bat.

7. The woman (remodeler) (motorist) lowered the beam

8. The woman (dieter) (attacker) deserved the belt.

9. The man (waiter) (senator) wrote the bill.

10. The woman (liar) (climber) described the bluff.

11. The man (carpenter) (argument) divided the board.

12. The man (archer) (groom) straightened the bow.

13. The woman (electrician) (florist) inserted the bulb.

14. The man (builder) (legislator) rejected the cabinet.

15. The man (rancher) (jogger) injured a calf.

16. The man (doctor) (harvester) liked the cane.

17. The man (clothier) (brewery) replaced the cap.

18. The woman (casino) (lovers) exchanged the cards.

19. The man (drunk) (attorney) finished a case.

20. The woman (invalid) (director) hated the cast.

21. The man (inmate) (virus) damaged the cell.

22. The man (cashier) (general) reviewed the charge.

23. The man (armor) (pirate) covered the chest.

24. The man (team) (cowboy) admired the coach.

25. The woman (statistician) (princess) knew the count.

26. The man (sophomore) (caddie) skipped the course.

27. The man (potter) (sailor) sold his craft.

28. The man (historian) (boyfriend) forgot the date.

29. The woman (scoutmaster) (lawyer) recorded the deed.

30. The man (appraiser) (umpire) measured the diamond.

31. The woman (baker) (miser) hoarded the dough.

32. The man (dentist) (marine) remembered the drill.

33. The woman (stuntman) (gardener) prepared for the fall.

34. The man (planters) (referee) rechecked the field.

35. The woman (artist) (accountant) scrutinized the figure.

36. The woman (clerk) (manicurist) acquired the file.

37. The man (chef) (duelist) grasped the foil

38. The man (tinsmith) (shepherd) inspected the fold.

39. The man (comedian) (kidnapper) used the gag.

40. The woman (wino) (children) enjoyed gin.

41. The woman (vandal) (barmaid) broke the glass.

42. The woman (developers) (cook) saved the grounds.

43. The woman (smoker) (nun) disliked the habit.

44. The woman (vegetarian) (audience) despised the ham.

45. The man (glove) (gambler) hid his hand.

46. The woman (dietician) (cab) bypassed the jam.

47. The man (welder) (addict) tested the joint.

48. The woman (doorman) (secretary) jammed the key.
49. The woman (manager) (politician) organized the lobby. 50. The man (burglar) (barber) cut the lock.

51. The man (lumberjack) (mathematician) transformed the log.

52. The woman (undergraduate) (private) requested the major.

53. The man (strongman) (priest) held the mass.

54. The woman (computer) (arsonist) found a match.

55. The woman (microbiologist) (designer) discarded the mold.

56. The woman (cat) (beautician) observed the mole.

57. The woman (roofer) (cosmetician) bent the nail.

58. The man (fisherman) (banker) showed the net.

59. The woman (church) (surgeon) refused the organ.

60. The man (poet) (farmer) emptied the pen.

61. The man (catcher) (synthesizer) changed the pitch.

62. The man (busboy) (coach) bumped the pitcher.

63. The man (pilot) (architect) leveled the plane.

64. The man (environmentalist) (billionaire) named the plant.

65. The man (all-star) (screenwriter) recollected the play.

66. The man (landscaper) (writer) developed the plot.

67. The man (navigator) (headwaiter) recommended the port.

68. The man (police) (newlywed) burned the pot.

69. The man (bride) (historian) preferred the present.

70. The woman (musician) (bookkeeper) kept the record.

71. The man (jeweler) (operator) modified the ring.

72. The man (mechanic) (parliament) blamed the ruler.

73. The woman (handyman) (theater) examined the screen.

74. The woman (zoo) (postmaster) saw the seal.

75. The woman (teacher) (judge) heard the sentence.

76. The woman (driver) (supervisor) switched the shift.

77. The woman (policeman) (medic) prevented the shot.

78. The woman (rascal) (paramedic) stored the sling.

79. The man (bird) (intern) removed the slug.

80. The woman (gravedigger) (cardsharp) offered the spade.

81. The woman (car) (bowler) needed a spare.

82. The woman (college) (vaulter) dropped the staff.

83. The man (cavalry) (vendor) ordered the stand.

84. The man (astronomer) (filmmaker) discovered a star.

85. The man (broker) (cattleman) auctioned his stock.

86. The man (cow) (drinker) chewed the straw.

87. The woman (lifeguard) (coroner) analyzed the stroke.

88. The man (cleaners) (bailiff) presented the suit.

89. The woman (radioman) (batter) tried the switch.

90. The man (salesman) (wrestler) got the tag.

91. The woman (insomniac) (dog) noticed the tick.

92. The woman (outfit) (tally) excluded the tie.

93. The man (mountaineer) (toymaker) made the top.

94. The women (key) (mammoth) scratched his trunk.

95. The man (mariner) (cardiologist) repaired the vessel.

96. The man (undertaker) (surfer) pictured the wake. 


\section{APPENDIX C}

Sentence Stimuli Employed in Experiment 3: Combined Verb and Subject Noun of Experiments 1 and 2

In each of the pairs of sentence stimuli, the order, indicated by the superscript in the first set, is as follows: adominant biased sentence, ${ }^{b}$ subordinate biased sentence.

1. The physician massaged his arms. ${ }^{\text {a }}$ The marksman discharged his arms. ${ }^{b}$

2. The juggler inflated the ball.

The ballerina catered the ball.

3. The collie heard the bark.

The botanist peeled the bark.

4. The runner stole the base.

The soldier patrolled the base.

5. The slugger splintered the bat.

The biologist wounded the bat.

6. The remodeler reinforced the beam.

The motorist focused the beam.

7. The drunk chugged a case.

The attorney defended a case.

8. The cashier billed the charge.

The general commanded the charge.

9. The statistician totaled the count.

The princess kissed the count.

10. The historian memorized the date. The boyfriend jilted the date.

11. The baker sweetened the dough. The miser spent the dough.

12. The stuntman broke the fall. The gardener preferred the fall.

13. The artist outlined the figure.

The accountant multiplied the figure.

14. The clerk reorganized the file. The manicurist dulled the file.

15. The chef wrinkled the foil.

The duelist thrust the foil.

16. The wino drank gin.

The children played gin.

17. The developers landscaped the grounds.

The cook percolated the grounds.

18. The burglar picked the lock.

The barber combed the lock.
19. The lumberjack chopped the log. The mathematician computed the log.

20. The undergraduate started the major. The private saluted the major.

21. The microbiologist cultured the mold. The designer cast the mold.

22 . The church tuned the organ. The surgeon implanted the organ.

23. The poet misplaced the pen. The farmer shoveled the pen.

24. The busboy spilled the pitcher. The coach introduced the pitcher.

25 . The police smuggled the pot. The newlywed scrubbed the pot.

26. The jeweler flaunted the ring. The operator silenced the ring.

27. The handyman shut the screen. The theater brightened the screen.

28. The zoo trained the seal. The postmaster licked the seal.

29. The driver ground the shift. The supervisor scheduled the shift.

30. The rascal loaded the sling. The paramedic prescribed the sling.

31. The gravedigger purchased the spade. The cardsharp trumped the spade.

32. The astronomer orbited a star. The filmmaker entertained a star.

33. The broker liquidated his stock. The cattleman slaughtered his stock.

34. The cleaners modeled the suit. The bailiff filed the suit.

35. The insomniac quieted the tick. The dog killed the tick.

36. The mariner torpedoed the vessel. The cardiologist ruptured the vessel. 


\section{APPENDIX D}

Sentence Stimuli Employed in Experiment 4: Replacement of the Ambiguous Word With Another Direct Object

In each of the following pairs of sentence stimuli, the superscripts given in the first pair indicate the adominant and ${ }^{b_{s}}$ dbordinate sentence frames from Experiment 3.

1. The physician massaged his wife. ${ }^{a}$ The marksman discharged his driver. ${ }^{b}$

2. The juggler inflated the price.

The ballerina catered the luncheon.

3. The collie heard the command.

The botanist peeled the onion.

4. The runner stole the trophy.

The soldier patrolled the streets.

5. The slugger splintered the bone.

The biologist wounded the snake.

6 . The cashier billed the police.

The general commanded the prisoners.

7. The statistician totaled the limousine.

The princess kissed the picture.

8. The baker sweetened the deal.

The miser spent the ammunition.

9. The stuntman broke the windows.

The gardener preferred the hybrid.

10. The artist outlined the plan.

The accountant multiplied the calls.

11. The clerk reorganized the staff.

The manicurist dulled the blade.

12. The chef wrinkled the hat.

The duelist thrust the note.

13. The wino drank tea.

The children played house.

14. The developers landscaped the park. The cook percolated the broth.

15. The burglar picked the neighborhood. The barber combed the area.

16. The lumberjack chopped the vegetables. The mathematician computed the program.
17. The undergraduate started the engine. The private saluted the children.

18. The microbiologist cultured the student. The designer cast the stone.

19. The church tuned the motor. The surgeon implanted the chip.

20. The poet misplaced the keys. The farmer shoveled the walk.

21. The busboy spilled the news. The coach introduced the speaker.

22. The police smuggled the tape. The newlywed scrubbed the tub.

23. The jeweler flaunted the fur. The operator silenced the caller.

24. The handyman shut the vent. The theater brightened the plaza.

25. The zoo trained the employee. The postmaster licked the wound.

26. The driver ground the coffee. The supervisor scheduled the party.

27. The rascal loaded the dice. The paramedic prescribed the drug.

28. The gravedigger purchased the tickets. The cardsharp trumped the loser.

29. The astronomer orbited a system. The filmmaker entertained a guest.

30. The broker liquidated his estate. The cattleman slaughtered his family.

31. The cleaners modeled the logos. The bailiff filed the wood.

32. The insomniac quieted the kids. The dog killed the intruder. 